\title{
Observations and Wind-Forced Model Simulations of the Mean Seasonal Cycle in Tropical Pacific Sea Surface Topography
}

\author{
Michael J. McPhaDen \\ NOAA Pacific Marine Environmental Laboratory, Seattle, Washington \\ ANTONIO J. BUSALACCHI \\ Laboratory for Oceans, NASA Goddard Space Flight Center, Greenbelt, Maryland
}

\author{
JoËL PICAUT
}

Groupe SURTROPAC, Office de la Recherche Scientifique et Technique Outre-Mer, Nouméa, New Caledonia

\begin{abstract}
We examine simulations of the mean seasonal cycle in the tropical Pacific using a multiple vertical mode linear numerical model forced with three different surface wind stress products averaged over the period 1979-1981. The model is run to equilibrium for each of four vertical modes, and results are summed. Simulated mean seasonal cycles in dynamic height and sea level are then compared with observed variations based on expendable bathythermograph and island tide gauge data averaged over the same 1979-1981 period. All simulations show characteristic features of the mean meridional ridgetrough structure in surface topography. However, north and south equatorial ridges at $20^{\circ} \mathrm{N}$ and $20^{\circ} \mathrm{S}$ are much higher than those observed, only weak equatorial ridges are generated near $4^{\circ} \mathrm{N}$, and none of the simulations exhibits a significant equatorial trough. These discrepancies are due principally to limitations in model physics and in the wind forcing. Observed and modeled mean seasonal variations in surface height are of the order of a few centimeters. Coherence estimates of $0.5-0.7$ are found between the model simulations and the observations for the 1 cycle per year harmonic, which dominates the seasonal cycle over most of the tropical Pacific. This suggests that about $25-50 \%$ of the variance in the observed annual surface height is accounted for by the linear model, given current estimates of the surface wind field. Harmonics higher than the annual are less well modeled because of their weaker signal levels. Regional patterns are observed in coherence levels between modeled and observed variability; i.e., longitudinally, the eastern Pacific is most poorly modeled, while latitudinally, the equatorial band $\left(5^{\circ} \mathrm{N}\right.$ to $5^{\circ} \mathrm{S}$ ) is best modeled. However, no wind stress product is clearly superior to the others for simulating the mean seasonal cycle. Thus uncertainty in the surface stress field remains a fundamental obstacle to more accurate modeling of the variability in tropical Pacific sea surface topography.
\end{abstract}

\section{Introduction}

Most model hindcasts of tropical Pacific Ocean variability have been restricted to the study of El Niño events. Busalacchi and O'Brien [1981], Busalacchi et al. [1983], and Busalacchi and Cane [1985] examined the sea level response of a linear model to estimates of wind field variability for specific years encompassing several major E1 Niños between 1961 and 1983. Cane [1984] used a linear model forced by composited wind anomalies to hindcast average El Niño conditions described by Rasmusson and Carpenter [1982]. Quantitative assessments of these simulations were performed by testing the solutions against sea level time series from scattered island and coastal tide gauges. Qualitative comparisons of observed and modeled equatorial current and subsurface temperature time series from 1982-1983 El Niño event have also been done with a more sophisticated ocean general circulation model (OGCM) [Philander and Seigel, 1985].

In view of the large interannual variability in the tropical Pacific, studies of the weaker mean seasonal cycle have been less frequent. Busalacchi and O'Brien [1980] and Gent [1985] have studied the-response of linear models to climatological mean seasonal wind forcing, and Philander et al. [1987] have

Copyright 1988 by the American Geophysical Union.

Paper number $8 \mathrm{C} 0290$ ORSTOM Fonds Documentaire 0148-0227/88/008C-0290\$05.00

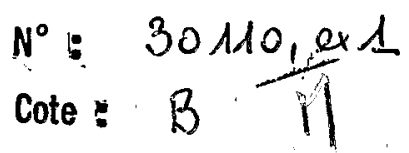

done so with an OGCM. It is difficult, however, to assess the accuracy of these seasonal simulations in part because the climatology of the forcing functions for the models is not necessarily computed over the same period of time as are the climatologies of the oceanic data used for comparison. Also, it is not clear to what extent simulations are adversely affected by surface wind stress errors, the magnitude and scales of which are generally not well known [e.g., Halpern and Harrison, 1982]. Furthermore, in evaluating model results, previous studies have relied on tide gauge data, current meter mooring data, and/or hydrographic data that tend to be regionally limited in their distribution. Thus inferences about model performance are generally confined to point comparisons within a particular region and not the basin as a whole.

The purpose of this study therefore is to quantitatively evaluate simulations of the mean seasonal cycle in the tropical Pacific Ocean on a very broad scale to different specifications of wind stress forcing. The model used is a linear, multiple vertical mode version of the model used by Busalacchi and O'Brien [1980]. The period of study will be 1979-1981, for which there are several coincident oceanic and surface wind data sets as well as a fairly regular seasonal cycle leading into the 1982-1983 El Niño. Mean seasonal dynamic height variations derived from an augmented version of the ship of opportunity (SOP) expendable bathythermograph (XBT) data set will be compared with the model solutions. The XBT data 

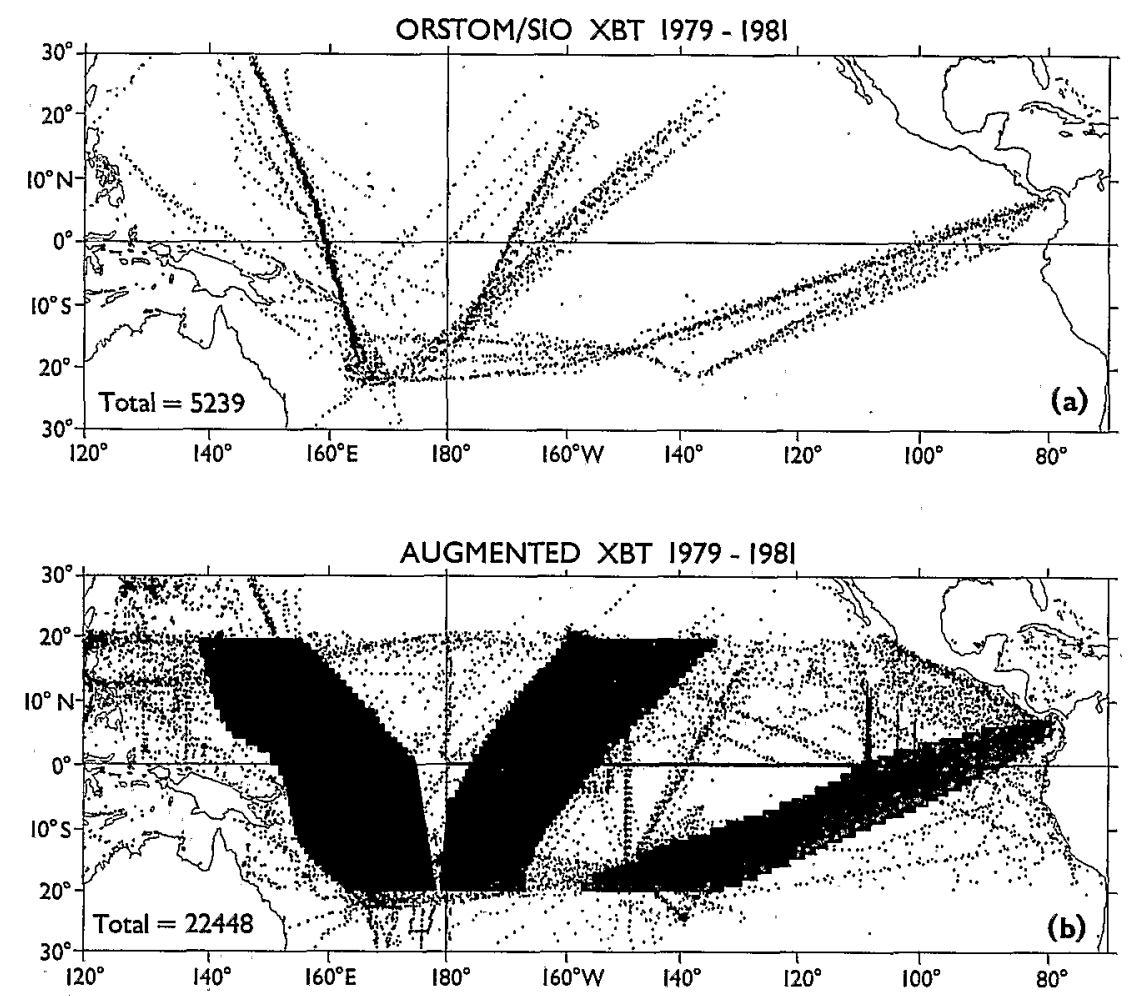

Fig. 1. Distribution of XBT data in the tropical Pacific for the period 1979-1981 for (a) data from the ORSTOM-SIO ship of opportunity program and $(b)$ the augmented XBT data set used in this study. Shaded areas in Figure $1 b$ indicate groupings of XBT data in the eastern, central, and western Pacific.

are concentrated along heavily traveled shipping lanes in the eastern, central, and western Pacific. Sea level data from the Tropical Ocean-Global Atmosphere (TOGA) Pacific sea level network [Wyrtki, 1985], which is concentrated in the central and western Pacific, will also be used in this study. To permit as broad based a comparison as possible, the model will be forced by the mean seasonal cycle of surface wind stress from three distinct wind analyses for 1979-1981, namely, the Florida State University (FSU) analysis [Goldenberg and O'Brien, 1981], the University of Hawaii (UH) analysis [Sadler and Kilonsky, 1985], and the Fleet Numerical Oceanography Center (FNOC) analysis [Harrison, 1984]. The differences among these wind products and how they affect the oceanic response will be of particular interest.

Results of these model studies have formed the basis for observing system simulation experiments in which the effects of aliased zonal variability have been evaluated [e.g., $M c P h a d-$ en et al., this issue]. Our results also provide background for studies of the 1982-1983 El Niño. Knowledge of the seasonal cycle is relevant for a definition of year-to-year anomalies; for a diagnosis of processes involved in the generation, maintenance, and decay of E1 Niño; and for an examination of the phase locking of the EI Niño anomalies to the annual cycle.

The plan for this paper is as follows. The oceanic data sets are described in section 2 , and the wind data sets used to force the model are discussed in section 3. Basin-scale similarities and differences in the three wind products are noted. Model formulation and description of the basin-scale sea level responses to the FSU, UH, and FNOC wind fields are presented in section 4. Intercomparisons between the ocean data and model solutions are discussed in section 5 .

\section{OCEANIC Data}

\subsection{Ship of Opportunity XBT Data}

In June 1979 the Office de la Recherche Scientifique et Technique Outre-Mer (ORSTOM) of Nouméa, New Caledonia, and Scripps Institution of Oceanography (SIO), La Jolla, California, organized an XBT ship of opportunity program in the tropical Pacific Ocean [Donguy and Meyers, 1987]. The program became fully operational in September 1980 between $20^{\circ} \mathrm{N}$ and $20^{\circ} \mathrm{S}$ and now provides XBT data routinely along several merchant ship lines as shown in Figure 1a. However, there have been many gaps longer than 1 month and several degrees of latitude due to problems with varying ship schedules, XBT supplies, and XBT failures. For the purposes of our work and for a more complete analysis over the 1979-1985 period, we have augmented the SOP data as much as possible in the region $70^{\circ} \mathrm{W}$ to $120^{\circ} \mathrm{E}, 20^{\circ} \mathrm{S}$ to $20^{\circ} \mathrm{N}$. The augmented data set used in this study is shown in Figure $1 b$. Details about data sources, quality control, and objective analysis to a uniform latitude-depth grid along the three main XBT transects shown in Figure $1 b$ will be given by J. Picaut et al. (manuscript in preparation, 1988) (hereinafter referred to as Picaut et al. (1988)). A summary is presented here with special attention on the 1979-1981 period of interest in the present study.

Five agencies responded to our requests for additional XBT data: the French Navy Hydrographic and Oceanographic Service (EPSHOM), Japan Oceanographic Data Center (JODC), the U.S. National Oceanographic Data Center (NODC), Commonwealth Scientific and Industrial Research Organization (CSIRO) of Australia, and Scripps Institution of Ocean- 
TABLE 1. List of Sources and Numbers of Casts of Thermal Data That Contributed to the Augmented Data Set Shown in Figure $1 b$

\begin{tabular}{lrrrr}
\hline \multicolumn{1}{c}{ Agency } & 1979 & 1980 & 1981 & Total \\
\hline ORSTOM/SIO & 792 & 1,902 & 2,545 & 5,239 \\
EPSHOM & 816 & 725 & 397 & 1,938 \\
JODC & 360 & 112 & 135 & 607 \\
NODC & 2,376 & 2,665 & 2,092 & 7,133 \\
SIO & 2,430 & 2,562 & 1,401 & 6,393 \\
ORSTOM & 981 & 48 & 109 & 1,138 \\
Total & 7,755 & 8,014 & 6,679 & 22,448 \\
\hline
\end{tabular}

Sources in addition to the ORSTOM-SIO ship of opportunity XBT program are the French Navy Hydrographic and Oceanographic Service (EPSHOM), Japan Oceanographic Data Center (JODC), the U.S. National Oceanographic Data Center (NODC), Scripps Institution of Oceanography (SIO), and thermal CTD and hydrocast profiles from ORSTOM-Nouméa (ORSTOM).

ography. We also added some thermal conductivitytemperature-depth (CTD) and hydrocast profiles from the ORSTOM-Nouméa data base in order to fill notable data gaps as occurred in the first half of 1979. Table 1 shows the number of thermal profiles per agency in our augmented file after elimination of duplicate data. For 1979-1981, we more than quadrupled (to 22,448 ) the number of data available from the ORSTOM-SIO SOP program (5239).

Despite such augmentation in data coverage, data are still concentrated mostly along the main shipping lines. Thus we have chosen to analyze the data in vertical sections, as Kessler and Taft [1987] did in the central Pacific, rather than to interpolate to a four-dimensional grid. We have grouped the data on a monthly basis without regard to longitude in the three regions outlined in Figure $1 b$ in the eastern, central, and western Pacific. Each region has been subjectively determined so that there is a minimum of one XBT per month per $1^{\circ}$ latitude band. The average data density is $2.4,3.6$, and 2.7 XBTs per month per degree latitude in the eastern, central, and western region, respectively. The large western region is explained by the fact that after March 1983 the single direct Nouméa-Japan track was replaced by two tracks displaced from the main route. The deepest depth considered is $400 \mathrm{~m}$, since $76 \%$ of the XBTs reach this depth as opposed to only $62 \%$ that reach $450 \mathrm{~m}$. Figure 2 shows that the data distribution in time over the three regions is fairly erratic, with a slight trend toward increasing data density in the eastern $\mathrm{Pa}$ cific and a slight trend toward decreasing data density in the central Pacific.

Several levels of subjective and objective quality control were applied to the temperature data (Picaut et al., 1988) before gridding in latitude and depth. Vertical sections were then smoothed by fitting the data at each depth to least squares determined Fourier components and eliminating all wave numbers higher than 0.33 cycles per degree of latitude. No smoothing in time was performed on the monthly data.

A dynamic height field relative to 400 dbar was derived from temperature using a mean temperature-salinity $(T-S)$ relationship from Levitus [1982]. This is a scheme simpler than the one used by Kessler and Taft [1987] which made use of observed SOP sea surface salinities. We found that their method does not necessarily improve dynamic height estimates in the western Pacific, where the mixed layers in salinity and temperature do not always coincide [Delcroix et al., 1987].
Errors in dynamic height calculations due to the use of a mean $T-S$ relation are probably $1-2$ dyn $\mathrm{cm}$ for individual XBT casts. Errors due to aliased internal waves, unstable 20to 30-day waves, and other high-frequency phenomena [e.g., Hayes, 1982] may also be 1-2 dyn $\mathrm{cm}$. These errors, to the extent that they are random, will be reduced by averaging in latitude and time. Grouping the data along transects without regard to longitude probably results in an additional error of 2 dyn $\mathrm{cm}$ [McPhaden et al., this issue]. This error can be larger where ship tracks are separated by more than $10^{\circ}$ of longitude, as occurs poleward of $16^{\circ} \mathrm{N}$ in the central Pacific and south of $8^{\circ} \mathrm{S}$ in the eastern Pacific. Estimates of the mean seasonal cycle can also be affected by year-to-year variations. Thus we expect uncertainties in our mean monthly dynamic heights to be at least about 2 dyn $\mathrm{cm}$.

\subsection{Sea Level Data}

The shallow thermocline and the baroclinic nature of seasonal variability in the tropics means that sea level and dynamic height relative to $400 \mathrm{dbar}$ are well correlated in our study region [e.g., Rebert et al., 1985]. Thus as a consistency check on results based on XBT data, we incorporate into our analysis data from the TOGA island sea level network [Wyrtki, 1985] for the period 1979-1981. Tide gauge data were processed to monthly means for each of 29 island stations shown in Figure 3. Data are concentrated in the western and central Pacific, with Santa Cruz in the Galápagos being the only instrumented island east of $150^{\circ} \mathrm{W}$. Median record length for all island stations is 33 months, and the shortest record is 15 months at Malden Island. Expected error in monthly mean sea level is typically less than $\lesssim 0.1 \mathrm{~cm}$ for monthly means [Wyrtki and Leslie, 1980].

\section{WIND DATA}

Wind data to drive the model have been chosen from the same years used to form the seasonal mean of the XBT and sea level observations, i.e., 1979-1981. This helps to eliminate ambiguities that result from comparing seasonal means of oceanographic observations taken at one period with model
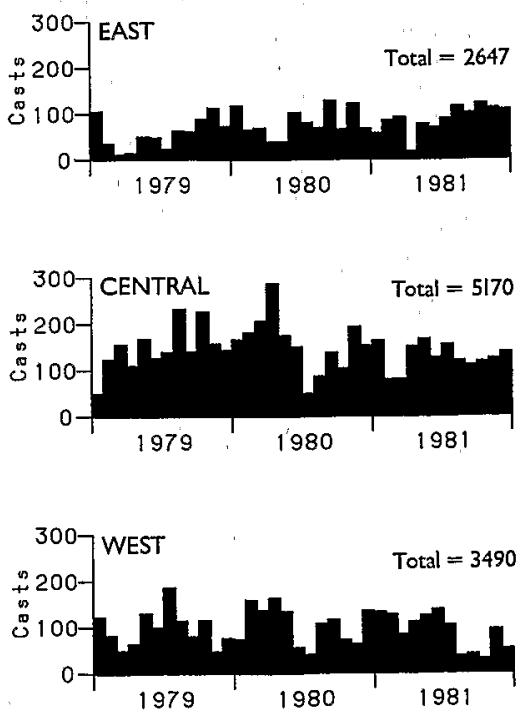

Fig. 2. Data distribution as a function of time in the eastern, central, and western Pacific for the augmented XBT data set shown in Figure $1 b$. 


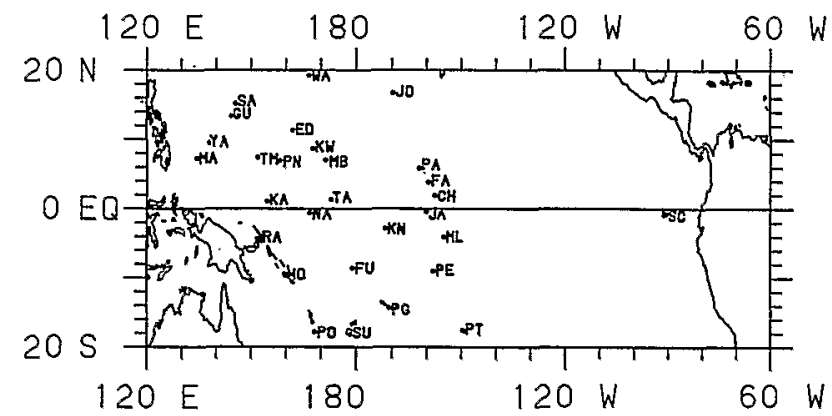

Fig. 3. Distribution of island sea level stations in the tropical Pacific. Islands are Christmas (CH), Enewetok (ED), Fanning (FA), Funafuti (FU), Guam (GU), Honiara (HO), Jarvis (JA), Johnston (JO), Kapingimarangi (KA), Kanton (KN), Kwajalein (KW), Malakal (MA), Majoro (MB), Malden (ML), Nauru (NA), Palmyra (PA), Penrhyn (PE), Pago Pago (PG), Ponape (PN), Port Villa (PO), Papeete (PT), Rabaul (RA), Saipan (SA), Santa Cruz (SC), Suva (SU), Tawara (TA), Truk (TM), Wake (WA), and Yap (YA).

solutions forced by climatological winds from another time. Moreover, we have chosen to utilize three wind products to enable an interpretation as to how some of the differences between the model solutions and the observations result from uncertainties in the analyzed wind data.

The model integrations are performed using three wind stress products for which monthly means are currently available for January 1979 through December 1981. Two of these data sets are derived from subjective analyses, and the third is derived from an operational objective analysis. One subjective analysis is the Florida State University (FSU) analysis of ship wind observations provided by J. J. O'Brien. The analysis procedure of transforming individual shipboard observations into wind pseudostress fields on a $2^{\circ} \times 2^{\circ}$ grid is described by Goldenberg and O'Brien [1981]. (Pseudostress is defined as the stress divided by air density and a constant drag coefficient.) Data density is generally adequate for determination of monthly mean wind stress, although ship wind data are very sparse (less than 4 observations per month per $2^{\circ}$ latitude by $10^{\circ}$ longitude box) in the southeastern tropical Pacific and in a broad area in the equatorial Pacific stretching from the date line to $110^{\circ} \mathrm{W}$.

The other subjective analysis is a combination of satelliteobserved, low-level cloud motions east of the date line, ship wind observations, island wind observations, and buoy wind observations performed by J. Sadler at the University of Hawaii. This derivation of monthly mean surface winds on a $2.5^{\circ} \times 2.5^{\circ}$ grid (referred to hereafter as UH) is described by Sadler and Kilonsky [1985]. Cloud motion vectors are extrapolated to the surface using a climatological estimate of boundary layer shear; west of the date line the analysis utilizes only surface observations, since no cloud motion vectors were available in the western Pacific during 1979-1981. Wind speed is then converted to pseudostress using a method similar to that described by Thompson et al. [1983] which takes into account wind variations on time scales of less than 1 month [Sadler et al., 1987].

The third data set we use is an objectively analyzed operational product from the Global Band Analyses of the United States Navy's Fleet Numerical Oceanography Center (FNOC) [Harrison, 1984]. An objective analysis based on Cressman [1959] is used on all reports (ship, island, buoy, etc.) in an operational data base for 6-hour intervals on a $2.5^{\circ} \times 2.5^{\circ}$ grid. A detailed comparison of wind velocity for the FSU, UH, and FNOC products for November 1979 is given by Halpern and Harrison [1982].

From each of these wind products the data from 1979-1981 have been used to form the 12 monthly means representing the mean seasonal cycle for this period. In the present study, a constant drag coefficient of $1.5 \times 10^{-3}$ and constant air density of $1.2 \mathrm{~kg} \mathrm{~m}^{-3}$ are used for all three data sets. The uncertainty in the drag coefficient is about 10-20\% [e.g., Large and Pond, 1981], implying an amplitude uncertainty in the model response of this amount.

The mean and standard deviation of each seasonal cycle are presented for the zonal wind stress (Figure 4), meridional wind stress (Figure 5), and wind stress curl (Figure 6). Similar largescale features are found in all the mean zonal wind strss fields (Figures $4 a, 4 c$, and $4 e$ ) and meridional wind stress fields (Figures $5 a, 5 c$, and $5 e$ ). The northeast and southeast trade winds are dominant over most of the basin. Core regions of the trades lie poleward of $10^{\circ}$, whereas weak mean westerlies are found equatorward of $10^{\circ}$ at the extreme ends of the basin. Mean UH easterlies are typically the strongest, and FNOC easterlies are the weakest; mean FNOC wind stress has the most small-scale structure, particularly within coastal regions, whereas the UH product is the smoothest. The smoothness of the UH product does not necessarily imply that it is a more accurate wind analysis. Rather, it reflects a bias of the analyst to smooth out small-scale features in order to emphasize the largest scales of variability. An interesting qualitative difference between the mean meridional winds is the position of the zero contour, which in the eastern and central Pacific delineates the approximate location of the intertropical convergence zone (ITCZ) between the northeast and southeast trades. In the FNOC winds this contour is several degrees closer to the equator than it is in the UH and FSU analyses.

The mean FSU and UH curl fields (Figures $6 a$ and $6 c$ ) have similar spatial structures, though UH curls are slightly larger and smoother. Both are characterized by a zonal band of positive curl in the northern hemisphere between about $4^{\circ} \mathrm{N}$ and $12^{\circ} \mathrm{N}$; in the southern hemisphere a region of positive curl oriented NW-SE separates two regions of negative curl. The mean curl distribution for the FNOC product (Figure 6e) is very different. The small-scale structure in the mean FNOC zonal and meridional wind stress fields is amplified in the curl field and tends to obscure the large-scale structure.

The variability of the seasonal cycle for zonal and meridional wind stress is summarized in the maps of the standard deviations in Figures $4 b, 4 d$, and $4 f$ and $5 b, 5 d$, and $5 f$. The annual excursion of the ITCZ appears as maxima of $0.2-0.4$ dyn $\mathrm{cm}^{-2}$ between $5^{\circ}$ and $15^{\circ} \mathrm{N}$ east of the date line in these fields. Maxima associated with monsoon variability over the far northwestern and southwestern Pacific are also robust features in all three wind products. In marked contrast, the nearequatorial band $\left(5^{\circ} \mathrm{N}\right.$ to $\left.5^{\circ} \mathrm{S}\right)$ and the southeastern quandrant of the tropical Pacific exhibit relatively.weak seasonal change. As in the mean fields, the FNOC standard deviation plots show more small-scale structure. The UH data generally have larger amplitudes, except near the coasts of Central America, Australia, and southeast Asia, where the FNOC winds are significantly stronger. In all three wind fields, $60-80 \%$ of the variability in the seasonal cycle is due to the annual harmonic.

As expected, the standard deviations of the wind stress curl (Figures $6 b, 6 d$, and $6 f$ ) reflect the variability of the individual wind stress components discussed above. The dominant fea- 

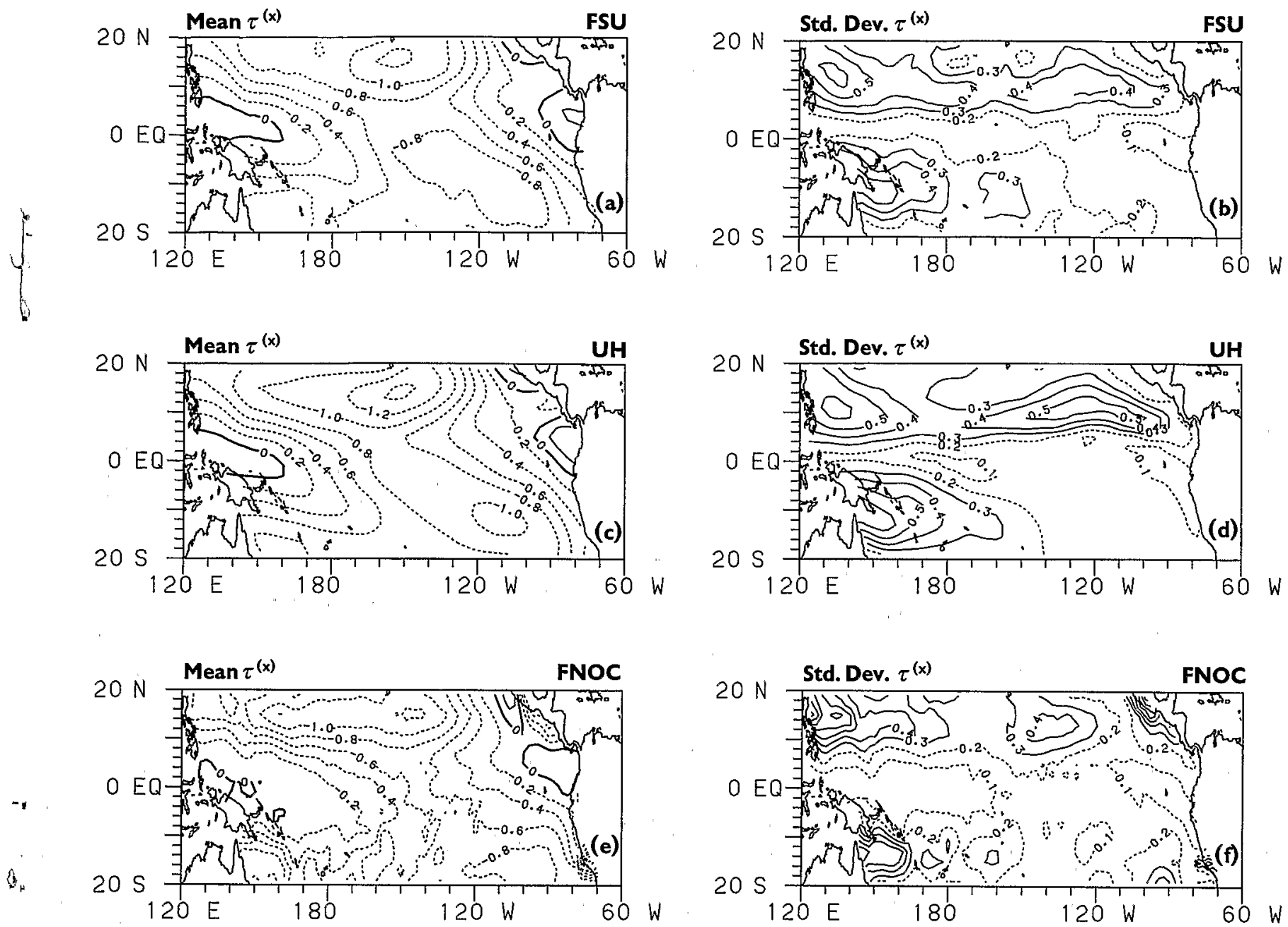

Fig. 4. FSU zonal wind stress $(a)$ mean and $(b)$ seasonal standard deviation, UH zonal wind stress $(c)$ mean and $(d)$ seasonal standard deviation, and FNOC zonal wind stress $(e)$ mean and $(f)$ seasonal standard deviation. Contours are in dyn $\mathrm{cm}^{-2}$. Dashed contours in Figures $4 a, 4 c$, and $4 f$ indicate westward wind stress. Dashed contours in Figures $4 b, 4 d$, and $4 f$ indicate regions where stress variability is less than $0.2 \mathrm{dyn} \mathrm{cm}^{-2}$.

tures in the UH curl variations are zonally oriented extrema on either side of the mean position of the ITCZ and a broad region of weak curl in the southeastern tropical Pacific. Patterns of weak variability in the southeastern quadrant and maxima on either side of the ITCZ in the eastern and central Pacific also appear in the FSU and FNOC analyses. However, the FSU and FNOC curl fields show greater small-scale variability, much (but perhaps not all) of which is noise related.

\section{MOdeling ApPROACH}

The model used in this study is similar to that employed by Busalacchi and O'Brien [1980]. A linear, numerical treatment of the shallow water wave equations is used to analyze the seasonal dynamic response of a model tropical Pacific Ocean to different representations of the surface wind stress. Changes to the previous version of the model include increased horizontal resolution of $40 \mathrm{~km}$ between like variables and a horizontal Laplacian friction of $10^{7} \mathrm{~cm}^{2} \mathrm{~s}^{-1}$. Sensitivity studies for the value of friction indicate little quantitative difference for changes to a factor of 5 . The model basin extends from $20^{\circ} \mathrm{N}$ to $20^{\circ} \mathrm{S}$ and $126^{\circ} \mathrm{E}$ to $70^{\circ} \mathrm{W}$. Open boundary conditions are applied at the northern and southern boundaries [Roed and
Smedstad, 1984] and a no-slip condition is imposed along the idealized coastal boundaries.

Busalacchi and Cane [1985] determined that at least two vertical modes are necessary to simulate sea level amplitudes on seasonal time scales in the equatorial waveguide. Hence we generated model height field solutions for the four gravest baroclinic modes of a Brunt-Väisälä frequency profile based on CTD data between $1.5^{\circ} \mathrm{N}$ and $1.5^{\circ} \mathrm{S}$ at $179^{\circ} \mathrm{W}$ as presented by Eriksen et al. [1983]. This profile was used because it is located in the equatorial waveguide in a region with significant wind stress fluctuations on seasonal and interannual time scales. The internal wave speeds for the four vertical modes are $c_{1}=2.90 \mathrm{~m} \mathrm{~s}^{-1}, c_{2}=1.77 \mathrm{~m} \mathrm{~s}^{-1}, c_{3}=1.13 \mathrm{~m} \mathrm{~s}^{-1}$, and $c_{4}=0.84 \mathrm{~m} \mathrm{~s}^{-1}$. A final solution is found by summing the individual contributions of all four modes. Modes 1 and 2 contribute most significantly to our results as in the work of Busalacchi and Cane [1985].

Owing to the range of the wave speeds, the time step of the model is mode dependent. All mode 1 calculations have a 1-hour time step, whereas the slower speeds of modes 2-4 permit a 2-hour time step without compromising numerical stability. Similarly, the time required for initial transients to 

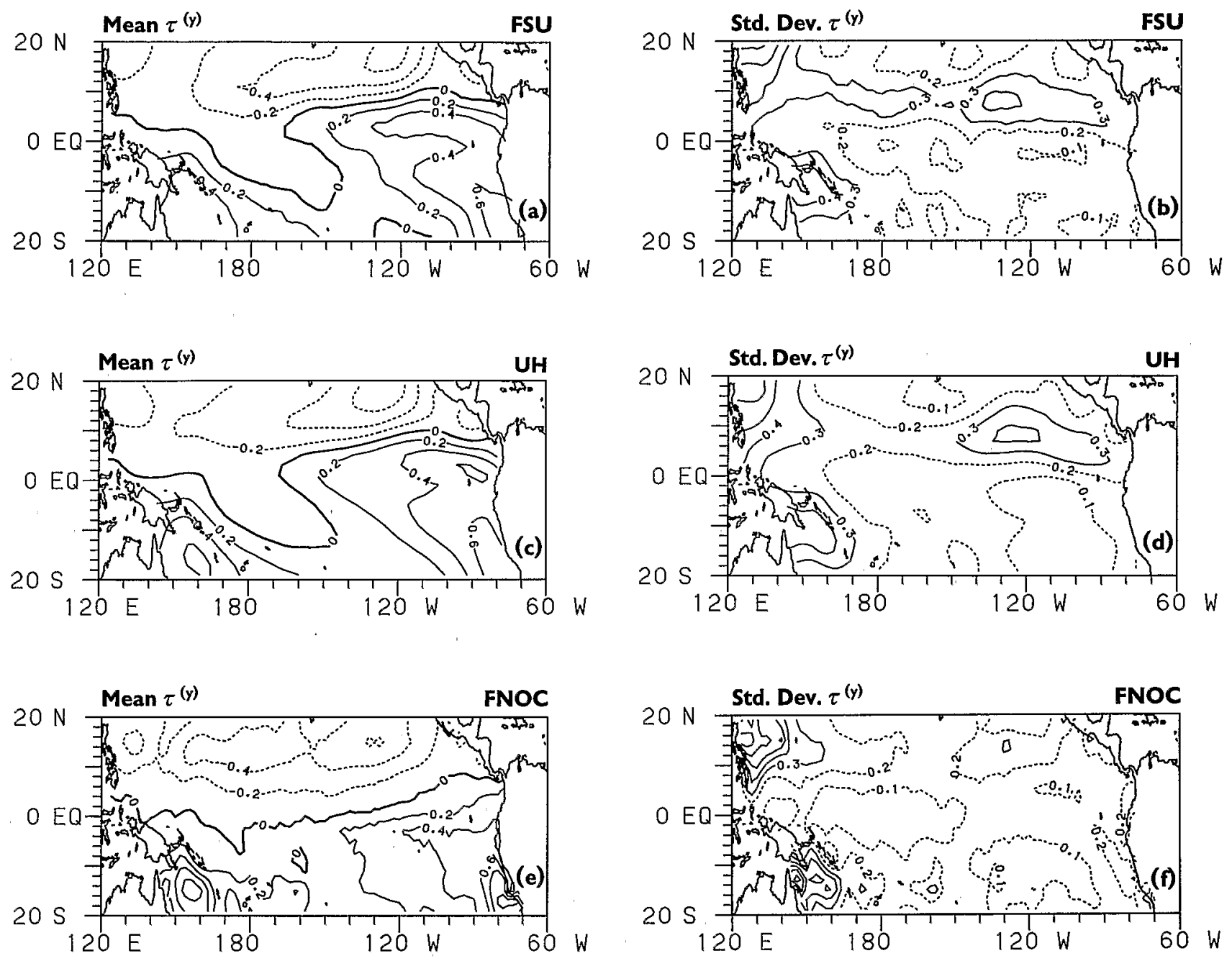

Fig. 5. Same as in Figure 4, but for meridional wind stress. Dashed contours in Figures $5 a, 5 c$, and $5 f$ indicate northward wind stress.

die out during spin-up is mode dependent. Beginning from a state of no motion and in response to the mean seasonal wind stress, an exact repeating seasonal cycle is obtained basin-wide after a spin-up of 12 years for mode 1,22 years for mode 2, 42 years for mode 3 , and 62 years for mode 4 . All the results that follow are taken from the last year of integration for each mode.

The mean sea levels modeled in response to these wind forcings are presented in Figure $7 a$ (FSU), Figure $8 a$ (UH), and Figure $9 a$ (FNOC). The sea level distributions are characterized by a system of zonally oriented troughs and ridges delineating major geostrophic currents in the model solutions. Between the sea level ridge of $20^{\circ} \mathrm{N}$ and the trough at $9^{\circ} \mathrm{N}$ flows a westward directed North Equatorial Current (NEC). An eastward flowing North Equatorial Countercurrent (NECC) is flanked by the NECC trough to the north $\left(9^{\circ} \mathrm{N}\right)$ and a weak equatorial ridge to the south $\left(2^{\circ}-4^{\circ} \mathrm{N}\right)$. This mean structure in the northern hemisphere is similar in all three solutions, reflecting large-scale similarities in the mean wind stress curl off the equator. Notably absent in the meridional topography of each solution is a clearly defined trough at the equator; furthermore, model equatorial ridges near $4^{\circ} \mathrm{N}$ are much less pronounced than are the observed ridges [e.g., Wyrtki, 1975].
The mean topography in the FSU and UH simulations is more structured in the northern hemisphere than in the southern hemisphere, where a weak South Equatorial Current (SEC) is situated between $6^{\circ}$ and $20^{\circ} \mathrm{S}$. By contrast, the FNOC solution exhibits more hemispheric symmetry in that a welldefined South Equatorial Countercurrent (SECC) trough, analogous to the NECC trough, is centered between $12^{\circ}$ and $15^{\circ} \mathrm{S}$. This structure is the response to the more continuous band of negative wind stress curl in the southern hemisphere vis-à-vis the FSU and UH fields (Figures $6 a, 6 c$, and $6 f$ ). Though the mean FNOC stress fields contain a great deal of small-scale structure, the response of the model ocean is predominantly large scale because horizontal mixing eliminates the smallest scales. Moreover, the interior ocean in the model is in Sverdrup balance, which involves a zonal integral of the winds from the eastern boundary. This tends to favor a largescale response by averaging out small-scale wind fluctuations.

The variability about the mean sea level is summarized by standard deviations of the seasonal cycles (Figures $7 b, 8 b$, and $9 b$ ). As in the winds, $60-80 \%$ of the variance is associated with the annual harmonic. Geographically, the largest seasonal changes occur in the northeastern portion of the basin. Of the three solutions, the amplitude of the UH response is the largest here with two maxima on either side of $8^{\circ} \mathrm{N}$ representing 

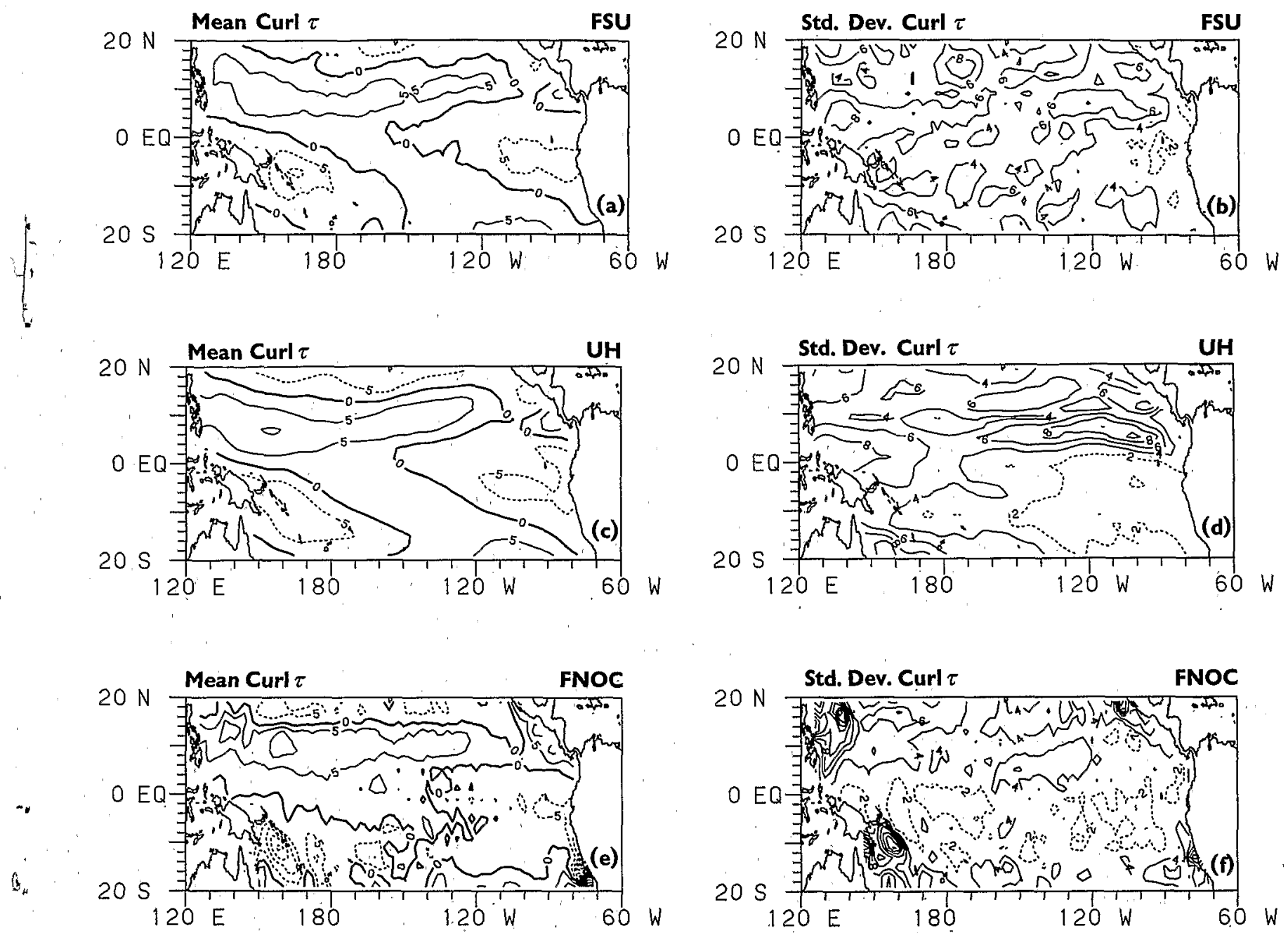

Fig. 6. Same as in Figure 4, but for wind stress curl (in $10^{-9}$ dyn $\mathrm{cm}^{-3}$ ). Dashed contours in Figures $6 a, 6 c$, and $6 f$ indicate negative curl. Dashed contours in Figures $6 b, 6 d$, and $6 f$ indicate regions where curl variability is less than

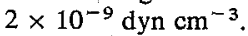

seasonal changes to the NEC-NECC system. These maxima tend to reflect the distribution of the variability in the wind stress curl, and as a result, the UH solution also has the largest zonal length scales. The sea level variability induced by the FSU winds is similar to the UH case north of $8^{\circ} \mathrm{N}$ but exhibits a less well defined maximum between the equator and $8^{\circ} \mathrm{N}$. This implies differences in current structures and in the zonal and meridional redistribution of mass in the two model simulations.

In contrast to the northern hemisphere, maxima in the southern hemisphere are smallest in the UH case because of the weak UH forcing south of the equator. The most distinctive southern hemispheric feature in the FSU and FNOC cases is a ridge of maximum variability extending SE-NW representing changes in the South Equatorial Current and South Equatorial Countercurrent. The FNOC induced sea level variability also appears more symmetric about the equator than does either the FSU or UH solution.

\section{MODEL-DATA ÍNTERCOMPARISON}

In this section we compare model sea levels and dynamic heights with oceanic counterparts derived from tide gauge and SOP XBT data. The SOP XBT data are grouped along sections in the eastern, central, and western Pacific as is discussed in section 2. For comparison with these data, we extract data from the mean seasonal model integrations along transects that closely approximate the mean position of XBT distributions in these regions. Model transects are represented as straight lines in latitude and longitude and are superimposed on the sea level standard deviation plots in Figures $7 b, 8 b$, and $9 b$. For comparison with tide gauge data, we extract sea level data from the model at island locations in Figure 3. Note that the largest model sea level signals occur in the northeastern quadrant of the basin and are not sampled by either the SOP XBT network or the sea level network.

We will initially focus the discussion in this section on the central Pacific, where there have been several observational studies of the seasonal cycle [e.g., "Meyers, 1979; Taft, 1981; Kessler and Taft, 1987] in order to introduce the more basinwide analysis to follow. For consistency with XBT measurements, model dynamic heights are computed relative to 400 dbar using the mean density profile centered at $0^{\circ} \mathrm{N}, 179^{\circ} \mathrm{W}$ plus vertical density profiles associated with variations in each vertical mode. These dynamic heights are highly correlated with model sea level, as are observed dynamic heights and sea level [e.g., Rebert et al., 1985].

Figure 10 shows the mean seasonal cycle of surface dynamic height relative to 400 dbar calculated from XBT data in the 


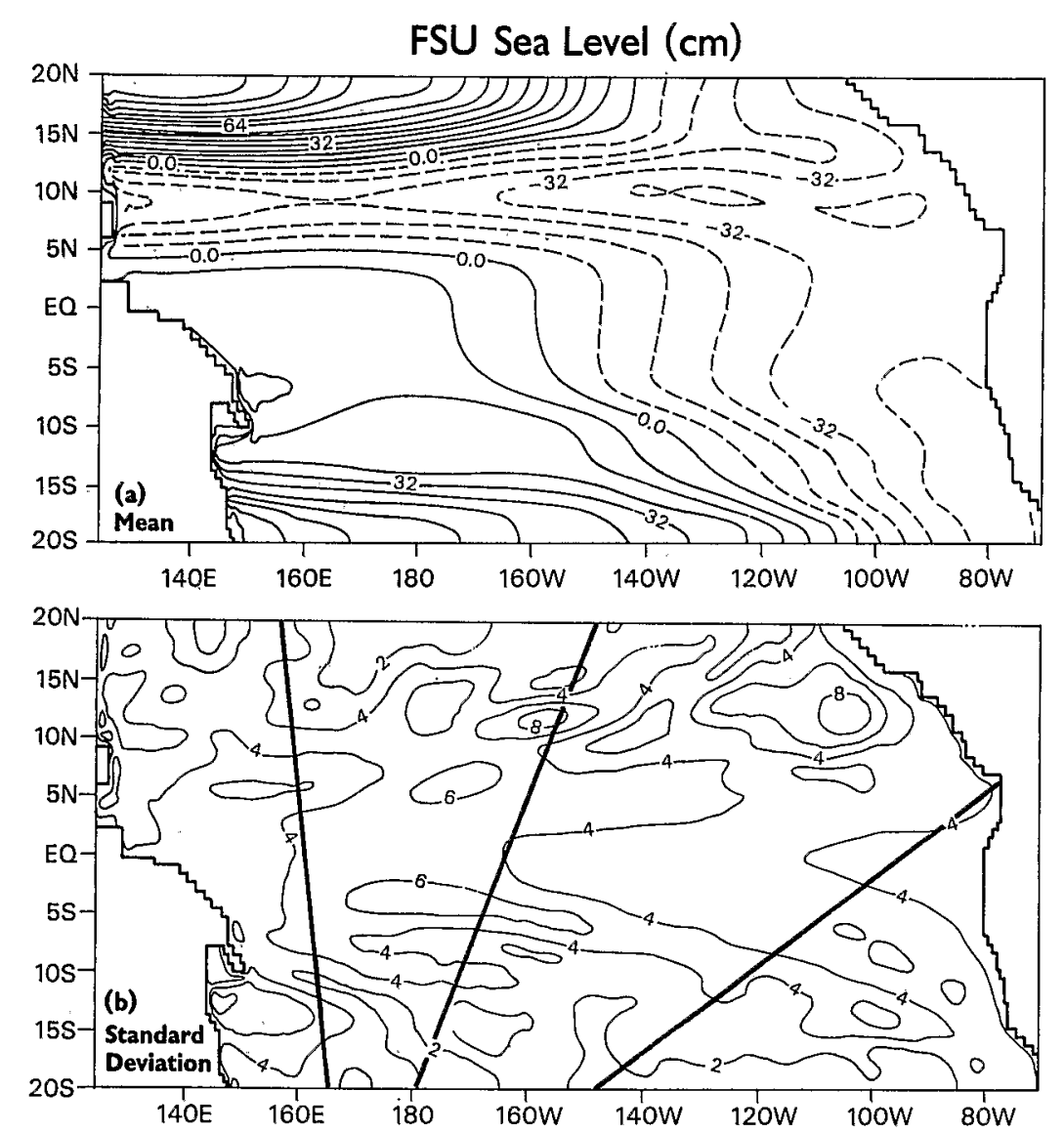

Fig. 7. Model sea level response to FSU wind forcing: $(a)$ mean and $(b)$ seasonal standard deviation (in centimeters). Heavy lines in Figure $7 b$ indicate the approximate mean position of XBT distributions in the eastern, central, and western Pacific.

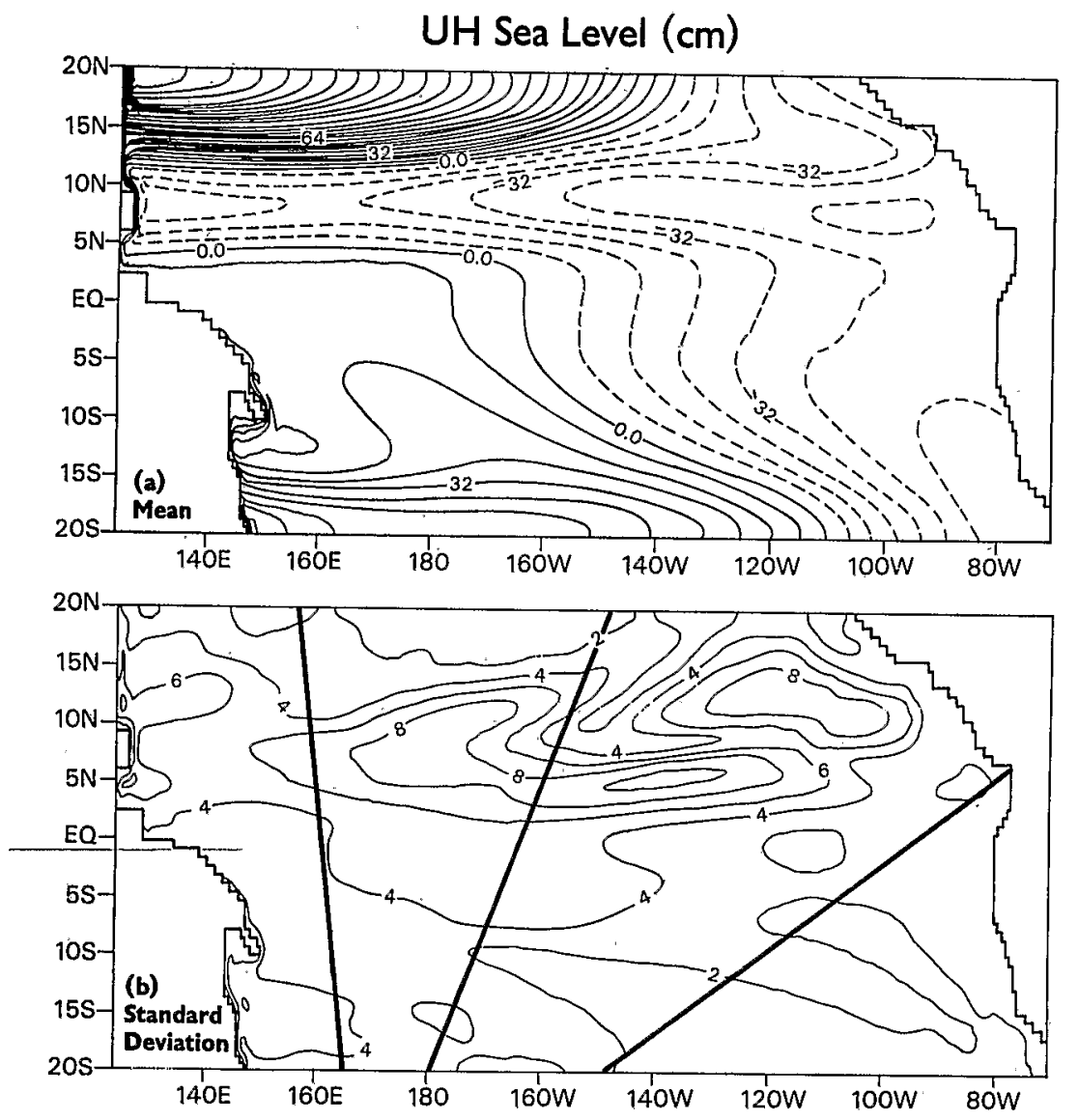

Fig. 8. Same as in Figure 7, but for UH wind forcing. 


\section{FNOC Sea Level $(\mathrm{cm})$}
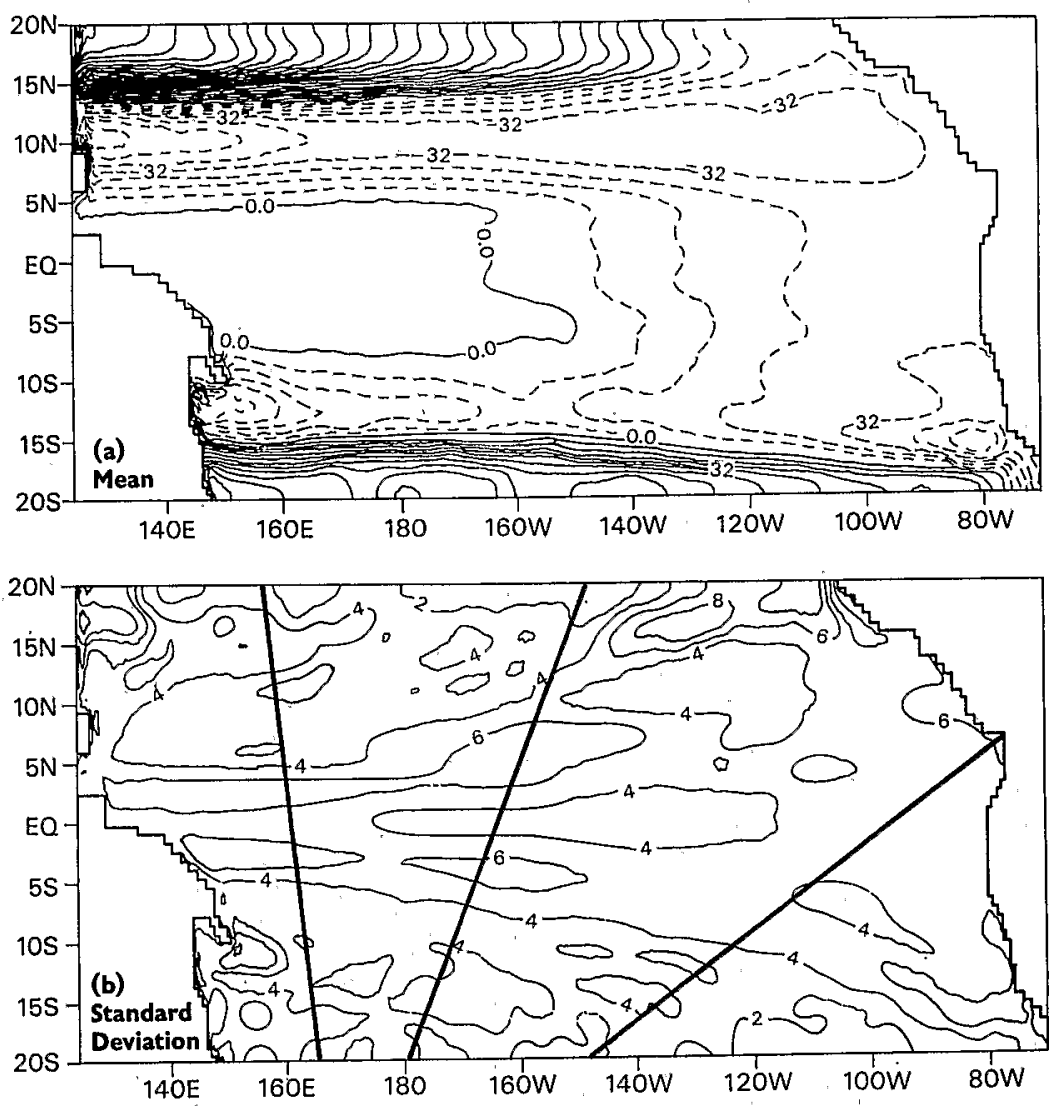

Fig. 9. Same as in Figure 7, but for FNOC wind forcing.

\section{XBT DATA}
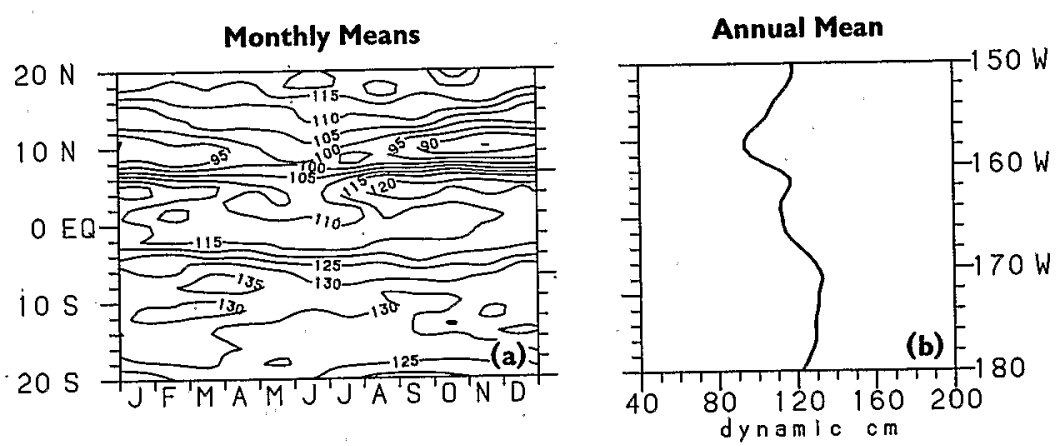

Monthly Anomalies
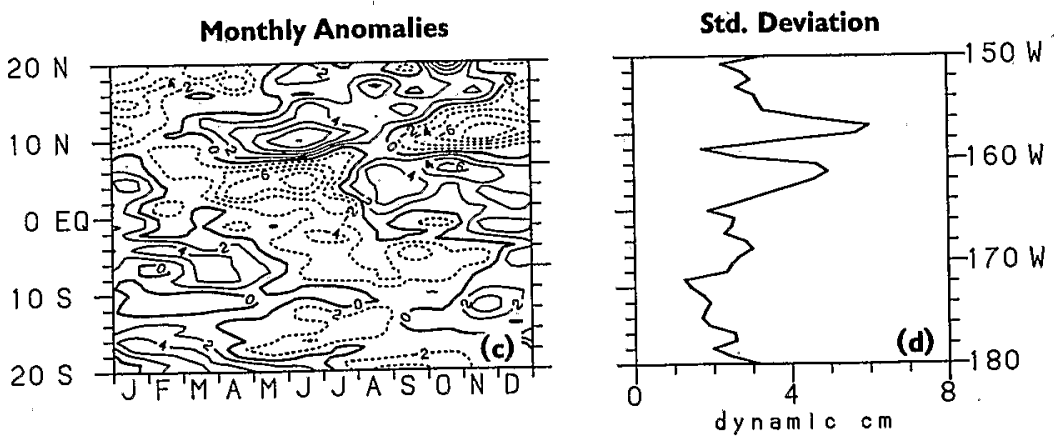

Fig. 10. XBT data processed to dynamic heights relative to $400 \mathrm{dbar}$ from the central Pacific swath of data in Figure $1 b$ : (a) monthly means, $(b)$ annual mean, $(c)$ monthly anomalies about the annual mean, and $(d)$ annual standard deviation computed from monthly anomalies. Contour intervals are $5 \mathrm{dyn} \mathrm{cm}$ for monthly means and $2 \mathrm{dyn} \mathrm{cm}$ for anomalies. 


\section{FSU SIMULATION}
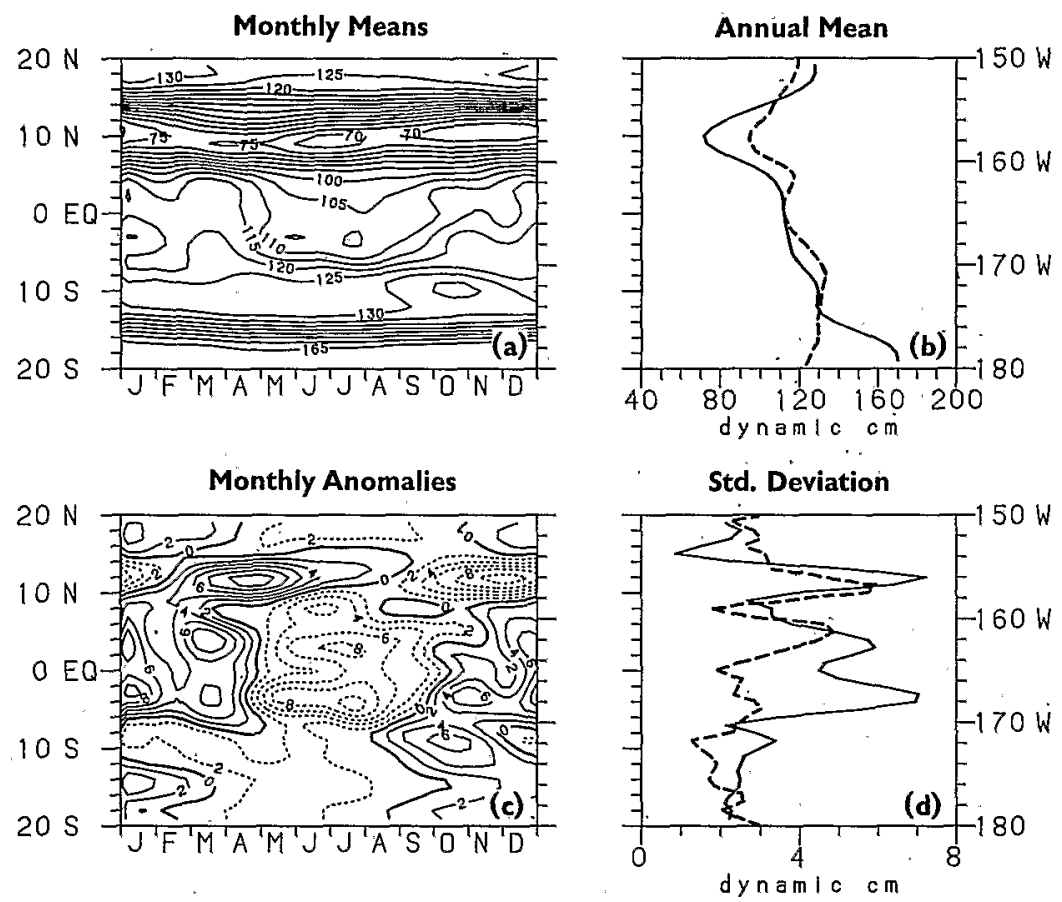

Fig. 11. Dynamic heights relative to $400 \mathrm{dbar}$ as in Figure 10 , but for the central Pacific grid point transect from the model forced by FSU winds. Dashed lines in Figures $11 b$ and $11 d$ are the annual mean and standard deviation from XBT data.

central Pacific. We see that the NECC trough is located at $10^{\circ} \mathrm{N}$ and is shallowest in boreal spring and deepest in boreal fall. There is an equatorial ridge at $5^{\circ} \mathrm{N}$ and an equatorial trough centered on the equator. Variability in the vicinity of the equatorial ridge and trough is in phase, with low sea level in spring and early summer and high sea level in the fall and winter. A SECC ridge near $8^{\circ} \mathrm{S}$ is highest in the spring and lowest in the fall. Typical standard deviations of monthly means across $20^{\circ} \mathrm{N}$ to $20^{\circ} \mathrm{S}$ are $2-3 \mathrm{dyn} \mathrm{cm}$, with values of 5-6 dyn $\mathrm{cm}$ in the vicinity of the NECC trough and equatorial ridge. Currents associated with this ridge-trough topography are the North Equatorial Current north of $10^{\circ} \mathrm{N}$, the North Equatorial Countercurrent between $5^{\circ} \mathrm{N}$ and $10^{\circ} \mathrm{N}$, the South Equatorial Current between $5^{\circ} \mathrm{N}$ and $8^{\circ} \mathrm{S}$, and the South Equatorial Countercurrent between $8^{\circ} \mathrm{S}$ and $12^{\circ} \mathrm{S}$.

Figure 11 shows the model transect taken from the central Pacific for the FSU simulation and processed to a mean seasonal cycle. We note that as in Figure 10, the NECC trough is located near $10^{\circ} \mathrm{N}$ and is shallowest in boreal spring and deepest in boreal fall: Similarly, near the equator, dynamic height is low in spring and summer and high in fall and winter. In the southern hemisphere the pattern of highs and lows in Figure $11 \mathrm{c}$ is also similar to that observed in the data in Figure $10 \mathrm{c}$. Model variations tend to be stronger than those in the XBT data, though as in the data an extremum in variability is found at $12^{\circ} \mathrm{N}$ near the NECC trough and another extremum is located near $3^{\circ}-4^{\circ} \mathrm{N}$ (Figure 11d). The large-amplitude variations in the model between $3^{\circ}$ and $4^{\circ} \mathrm{S}$ are not seen in the data, however.

Analysis of the vorticity balance in the model indicates that dynamic height variance in the vicinity of the NECC trough results from a combination of local Ekman pumping and Rossby wave radiation. Evidence for Rossby wave radiation in both hemispheres is seen in the tilt of anomaly extrema with time poleward of about $10^{\circ}$ (Figure $11 c$; also see Figures $12 c$ and $13 \mathrm{c}$ ). Rossby waves propagate faster to the west at lower latitudes than at higher latitudes, so that a wave train generated in the eastern Pacific arrives in the central Pacific at progressively later times with increasing latitude. Ekman pumping is comparable to Rossby wave induced variability in the model at $10^{\circ} \mathrm{S}$ near a weakly defined. SECC ridge and from $16^{\circ} \mathrm{S}$ and $20^{\circ} \mathrm{S}$, consistent with analyses of ocean temperature data by Meyer [1979] and Kessler and Taft [1987]. Equatorial Rossby waves contribute significantly to the high model variance at $3^{\circ}-4^{\circ} \mathrm{N}$ and $3^{\circ}-4^{\circ} \mathrm{S}$.

There are a number of major differences between the XBT and the model transects, however, which are due principally to differences in the mean fields. The mean model surface topography for the FSU run (Figure 11b) shows very high north and south equatorial ridges near $20^{\circ} \mathrm{N}$ and $20^{\circ} \mathrm{S}$; a deeper than observed NECC trough at $10^{\circ} \mathrm{N}$, a plateau rather than a ridge near $4^{\circ} \mathrm{N}$, and no equatorial trough. We suggest that the lack of a model equatorial trough is due to the absence of vertical mixing, nonlinearity, and thermodynamics which allow for a mean Equatorial Undercurrent and associated cooling of the sea surface via equatorial upwelling. The lack of a pronounced equatorial ridge is probably due in part to the linearity of the model. Philander and Pacanowski [1987] have shown in an OGCM that cross-equatorial advection of westward momentum from the southern to the northern hemisphere in response to southeast trade wind forcing intensifies the SEC near $3^{\circ} \mathrm{N}$. This implies a more pronounced equatorial ridge, since the SEC is primarily a geostrophically balanced flow. Coarse $2^{\circ}$ meridional resolution of the wind field could also contribute to a weaker than expected equatorial ridge, since it may lead to underestimates of the wind stress curl amplitude. 


\section{UH SIMULATION}
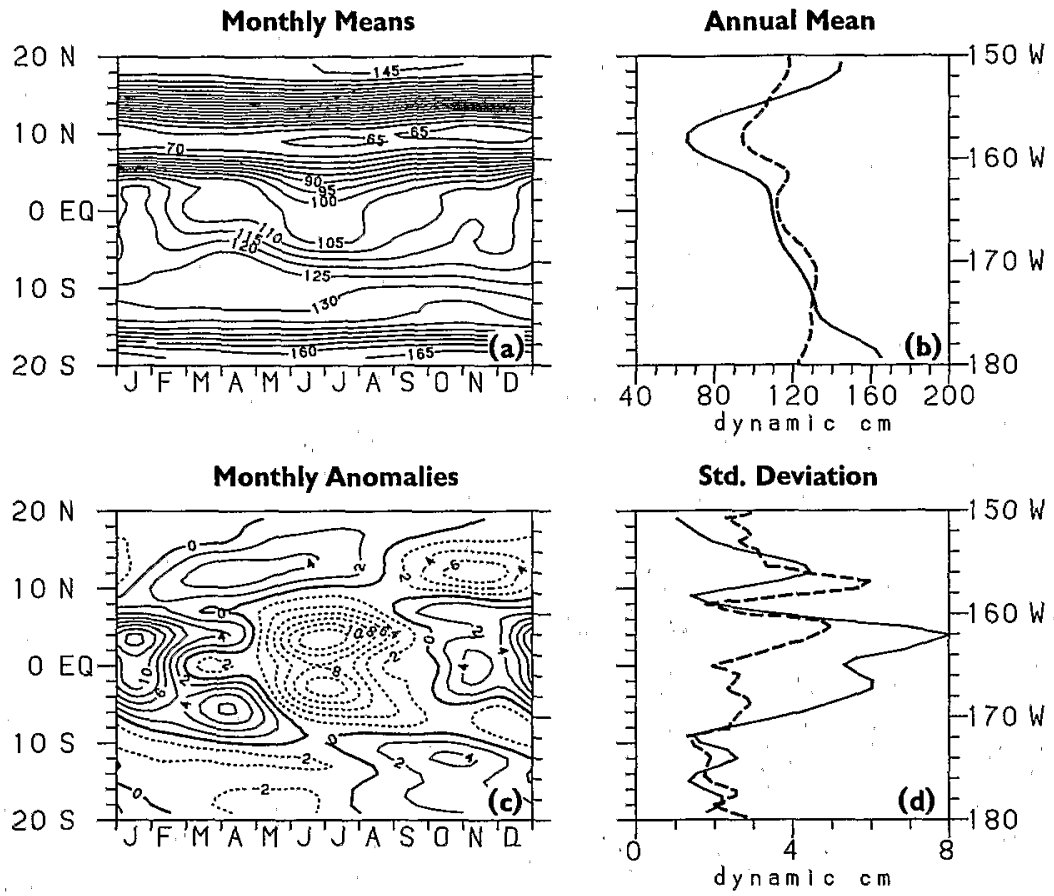

Fig. 12. Dynamic heights relative to $400 \mathrm{dbar}$ as in Figure 10, but for the central Pacific grid point transect from the model forced by UH winds. Dashed lines in Figures $12 b$ and $12 d$ are the annual mean and standard deviation from XBT data.

The high north and south equatorial ridges may result from the fact that the model phase speeds have been chosen from a Väisälä frequency profile typical of the central and western equatorial Pacific. The sharp thermocline there leads to an oceanic response which is weighted more toward the first and second vertical modes, which have larger signatures in sea level than do higher vertical modes. Choosing a Väisälä frequency profile typical of the weaker stratification in the subtropical gyres would result in a relatively stronger model response in higher vertical modes which have a weaker sea level signature.

We note that choosing a drag coefficient closer to 1.2 $\times 10^{-3}$ for the winds as suggested by Large and Pond [1981] would reduce the mean model topographic relief by $20 \%$. This would diminish, but not eliminate, discrepancies between observed and modeled structures in Figure $11 b$. Also, adding more vertical modes to the model will have little effect on the results. The winds project very weakly onto vertical modes higher than modes 1 and 2 which dominate the model sea level response [e.g. Cane, 1984]. Moreover, by inspection of the linear, steady state equatorial $\beta$ plane equations which govern mean conditions in our system [see Busalacchi and O'Brien, 1980], one can determine that the horizontal structure of the mean response in each vertical mode is identical. Thus higher vertical modes can change the ridge-trough topography shown in Figure $11 b$, quantitatively but not qualitatively.

There are also major discrepancies between the observed and modeled time variability. We noted already the Rossby wave induced maximum in dynamic height near $4^{\circ} \mathrm{S}$ which is absent in the data (Figure 11d). The model section also shows an SECC ridge which is best developed in boreal fall near $10^{\circ} \mathrm{S}$ as compared with near $8^{\circ} \mathrm{S}$ in boreal spring in the data (compare Figures $10 a$ and $11 a$ ). This leads to a model SECC that is strongest in the fall compared with an observed SECC which is strongest in the spring. The difference in timing of the SECC appearance in the model is due to the large difference in the mean dynamic topography, however, upon which is superimposed only slightly different time-latitude variations.

Figure 12 shows the corresponding dynamic height transect for the UH calculation. The mean ridge-trough structure is similar to that for the FSU calculation but with higheramplitude relief in the northern hemisphere, where the $\mathrm{UH}$ curl tends to be stronger. Amplitude and phase of variations about this mean are likewise similar to the FSU calculation. For example, the NECC trough is shallow in the spring and deep in the fall and dynamic height is low between $5^{\circ} \mathrm{N}$ and $5^{\circ} \mathrm{S}$ in the spring and summer and high in fall and winter. Peaks in variance are located at $12^{\circ} \mathrm{N}, 4^{\circ} \mathrm{N}$, and $3^{\circ} \mathrm{S}$, with the $12^{\circ} \mathrm{N}$ peak weaker and the $4^{\circ} \mathrm{N}$ peak stronger than in the FSU calculation. The dynamics responsible for height variations in this model run are essentially the same as for the FSU run.

Figure 13 shows dynamic height in the central Pacific for the FNOC simulation. Mean topography north of about $5^{\circ} \mathrm{S}$ resembles that in the FSU and $\mathrm{UH}$ calculations in that an $\mathrm{NECC}$ trough is found at $10^{\circ} \mathrm{N}$, a high north equatorial ridge is found near $17^{\circ} \mathrm{N}$, and there is no pronounced equatorial ridge-trough structure. Variations about the mean are usually lower in amplitude than they are for either the FSU or UH calculation, although the phasing of fluctuations and latitudinal position of extrema are similar. The peak in variability which appears near $12^{\circ} \mathrm{N}$ in both the FSU and UH calculations is present for example in the FNOC results but is greatly diminished (Figure 13d). The relative weakness of the response is due to weaker large scale wind variations in this product compared to the others (see Figures $4 f, 5 f$, and $6 f$ ). One of the 


\section{FNOC SIMULATION}
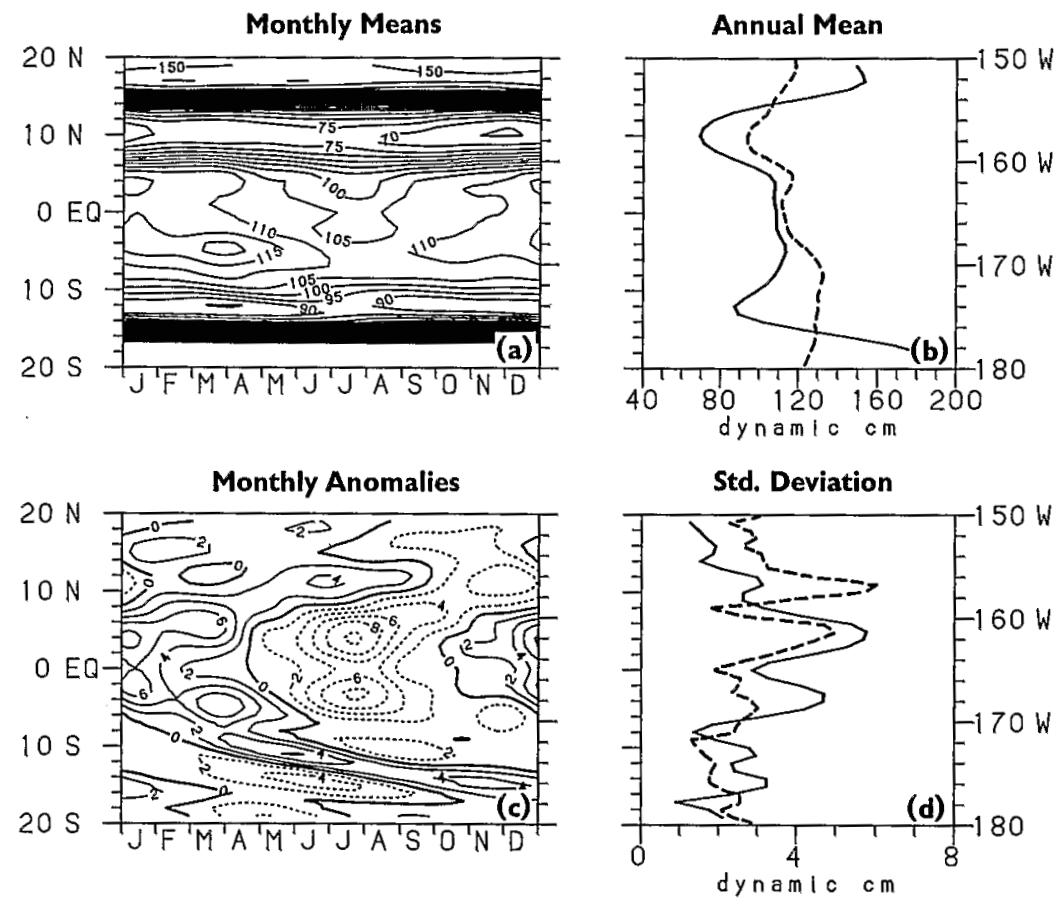

Fig. 13. Dynamic heights relative to $400 \mathrm{dbar}$ as in Figure 10, but for the central Pacific grid point transect from the model forced by FNOC winds. Dashed lines in Figures $13 b$ and $13 d$ are the annual mean and standard deviation from XBT data.

most significant differences between this calculation and the others, however, is the presence of a mean SECC trough at $12^{\circ} \mathrm{S}$ which is due to the greater zonal extent of the mean negative curl field in the southern hemisphere. This results in a SECC present at all times of the year between about $6^{\circ} \mathrm{S}$ and $12^{\circ} \mathrm{S}$, though variations in this latitude band bear some resemblance to those observed in the XBT data (compare Figures $10 c$ and $13 c$ ).

Figure 14 shows latitudinally averaged dynamic height variance as a function of frequency for the XBT data and each of the model simulations in the eastern, central, and western $\mathrm{Pa}-$ cific. In each case the spectra are red with most variance (75$90 \%$ ) at 1 cycle per year (cpy). Variance at 1 cpy is generally higher on the western and central transects than on the eastern transect because the latter is mostly confined to the southern hemisphere, where wind forcing is weak. The FSU and $\mathrm{UH}$ variances at $1 \mathrm{cpy}$ are always higher than the XBT and
FNOC variances except in the eastern Pacific, where UH winds are the weakest of all three forcing functions and the model response is correspondingly low. The spread of values at $1 \mathrm{cpy}$ is less than the difference between 1-cpy and 2-cpy variances in the western and central Pacific. Along all tracks the greatest differences are found at the higher frequencies.

To quantify the degree of correspondence between the model solutions and the XBT data, we computed coherence and phase as a function of frequency and latitude along each track. Results for 1-cpy dynamic heights averaged across all latitudes are presented in Table 2. Phase differences of less than 1 month are probably not significant because we used monthly wind forcing in the model and because XBT data were binned into monthly averages. Approximate significance levels can be determined by assuming independent estimates every $3^{\circ}$ of latitude based on a meridional decorrelation scale of about $300 \mathrm{~km}$ for seasonal variations [White et al., 1985].
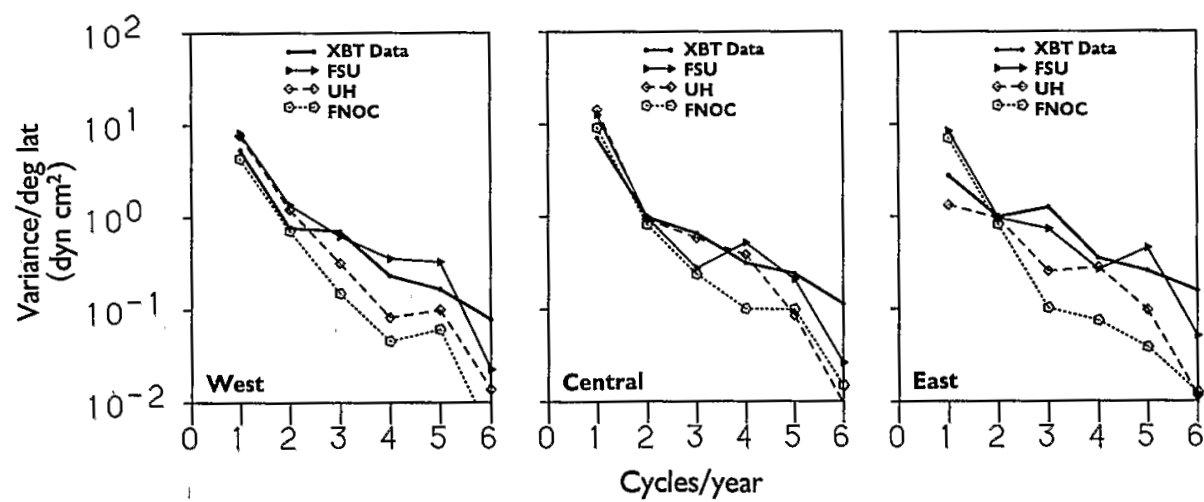

Fig. 14. Average variance per degree of latitude (in $d y n \mathrm{~cm}^{2}$ ) as a function of frequency from the XBT data and model simulations in the eastern, central, and western Pacific. 
TABLE 2. Coherence and Phase (in Months) Between Dynamic Heights Relative to 400 dbar Calculated From XBT Data and From Model Simulations Along Three Transects in the Eastern, Central, and Western Pacific

\begin{tabular}{lcccccccc}
\hline & \multicolumn{2}{c}{ West } & & \multicolumn{2}{c}{ Central } & & \multicolumn{2}{c}{ East } \\
\cline { 2 - 3 } & Coherence & Phase & & Coherence & Phase & & Coherence & Phase \\
\hline XBT-FSU & $\mathbf{0 . 7 3}$ & $\mathbf{- 1 . 6}$ & $\mathbf{0 . 4 3}$ & $\mathbf{0 . 0}$ & & 0.42 & 3.2 \\
XBT-UH & $\mathbf{0 . 5 8}$ & $\mathbf{- 1 . 0}$ & & $\mathbf{0 . 5 3}$ & $\mathbf{0 . 4}$ & & 0.29 & 4.8 \\
XBT-FNOC & 0.30 & $\mathbf{0 . 0}$ & & $\mathbf{0 . 4 7}$ & $\mathbf{1 . 2}$ & & $\mathbf{0 . 5 3}$ & $\mathbf{4 . 9}$ \\
\hline
\end{tabular}

Ninety percent confidence levels for coherence are 0.42 in the central and western Pacific and 0.50 in the eastern Pacific. Coherences which are significantly nonzero at this level are shown in bold type. Positive (negative) phase means the XBT dynamic heights lead (lag) model simulated dynamic heights.

This leads to $90 \%$ confidence levels for coherence of 0.42 along the western and central tracks, which span $39^{\circ}$ of latitude, and 0.50 along the eastern track, which spans $27^{\circ}$ of latitude. Values falling below these levels are probably not different from zero.

The best model coherence with XBT data anywhere in the Pacific is for the FSU-XBT pair on the western track, where coherence is 0.73 with the XBT data lagging by 1.6 months. The relatively high coherence is due to the fact that most XBT data are taken along a single transect during 1979-1981, that ship wind observations are relatively dense around this same transect (about 30 per month per $2^{\circ}$ latitude by $10^{\circ}$ longitude box), and that the seasonal variations in the winds are large (Figures 4-6). Coherence of the UH-XBT pair is also significant at 0.58 with a 1 -month phase difference, whereas the FNOC-XBT coherence is below the $90 \%$ confidence level in the west. All coherences are above the $90 \%$ significance level in the central Pacific, with phase differences of about a month or less. The UH-XBT pair shows the highest coherence in the central Pacific at 0.53 , possibly due to the fact that ship wind observations are relatively sparse (about 3 per month in some areas), whereas cloud motion vectors are plentiful in the central Pacific [e.g. Halpern and Harrison, 1982].

The eastern Pacific appears to be the most poorly modeled region of the basin. Only the FNOC-XBT coherence exceeds the $90 \%$ significance level; however, the phase difference for this pair is almost 5 months. Poor coherence and phase agreement in the eastern Pacific is probably due to weak wind forcing and an equally weak response. Contributing factors include poor ship wind data coverage in the southeastern Pacific (in the case of the FSU and FNOC products) and the use of a Väiälä frequency profile in the model representative of the western and central Pacific rather than the weaker stratification of the eastern Pacific. Phase speeds of vertical modes based on Väisälä frequency profiles are significantly lower in the eastern Pacific than in the west [e.g., Eriksen et al., 1983], so one would expect phases to be biased in our model simulations in the eastern Pacific. In addition, the very low coherence in the east between the UH model calculation and the XBT data may be due to errors in inferring surface winds from cloud motions near the equator, where large climatological shears exist between cloud wind level and the surface [Sadler and Kilonsky, 1985]. Noise in the XBT data due to track separation south of about $8^{\circ} \mathrm{S}$ [McPhaden et al., this issue] is probably also a factor in the low coherences in the east.

Figure 15 shows coherence and phase plots for each of the three model calculations with the XBT data at 1 cpy in three latitudinal ranges of $5^{\circ} \mathrm{S}$ to $15^{\circ} \mathrm{S}, 5^{\circ} \mathrm{S}$ to $5^{\circ} \mathrm{N}$, and $5^{\circ} \mathrm{N}$ to $15^{\circ} \mathrm{N}$.
Coherence values are higher than those in Table 1 because of the artificial coherence resulting from fewer degrees of freedom. Assuming that every third degree of latitude is independent, the $90 \%$ confidence limit for the null hypothesis is 0.76 . Not all of the differences in coherence levels seen in Figure 15 are statistically significant because of the limited numbers of degrees of freedom. However, the coherence patterns have a consistent physical interpretation which we elaborate on below.

Figure 15 shows a pattern of high coherence (0.6-0.9) and phase differences less than 2 months (except in the east) in the equatorial band. This high coherence is due to the fact that variability in dynamic height along the equator is proportional to a zonal integral of the zonal winds which tends to average out the effects of small-scale noise in the wind products [e.g., Busalacchi and Cane, 1985]. Coherence in general drops away from the equator, with biggest decreases typically occurring in the FNOC-XBT coherences. Off-equatorial coherences are lower because at higher latitudes, variability in dynamic height is proportional to wind stress curl, which involves spatial derivatives of the wind field. Therefore noise in the wind field is amplified, which degrades the accuracy of the simulation. There is a suggestion of hemispheric asymmetry to the coherence patterns in Figure 15, but differences are not statistically significant.

We have repeated these coherence calculations using model output sampled at the times and locations of actual XBT casts for a 3-year simulation (1979-1981) as opposed to the grid point transects shown in Figures 7-9. Model XBT data were averaged in time to produce a mean seasonal cycle in the eastern, central, and western Pacific areas outlined in Figure 1 as discussed by McPhaden et al. [this issue]. The coherences were generally lower than those in Table 2 for this sampling scheme because of the additional noise introduced by aliasing of zonal variations in the model. However, the differences were generally not significant. For example, coherences for the XBT-FSU pair in the eastern, central, and western Pacific were $0.61,0.38$, and 0.49 for the XBT sampled model output compared with $0.73,0.43$, and 0.42 for the grid point sampled output.

We have also repeated these coherence calculations for frequencies higher than $1 \mathrm{cpy}$ and found that they are generally lower and less consistent than those at 1 cpy because of the weaker signals at higher frequency (e.g., Figure 14). Similarly, we have computed coherences for geostrophic transport per unit width (i.e., depth-integrated geostrophic velocity) orthogonal to the transects poleward of $2^{\circ}$ latitude. Transport is a spatial derivative, i.e., high-pass-filtered version, of the dynam- 

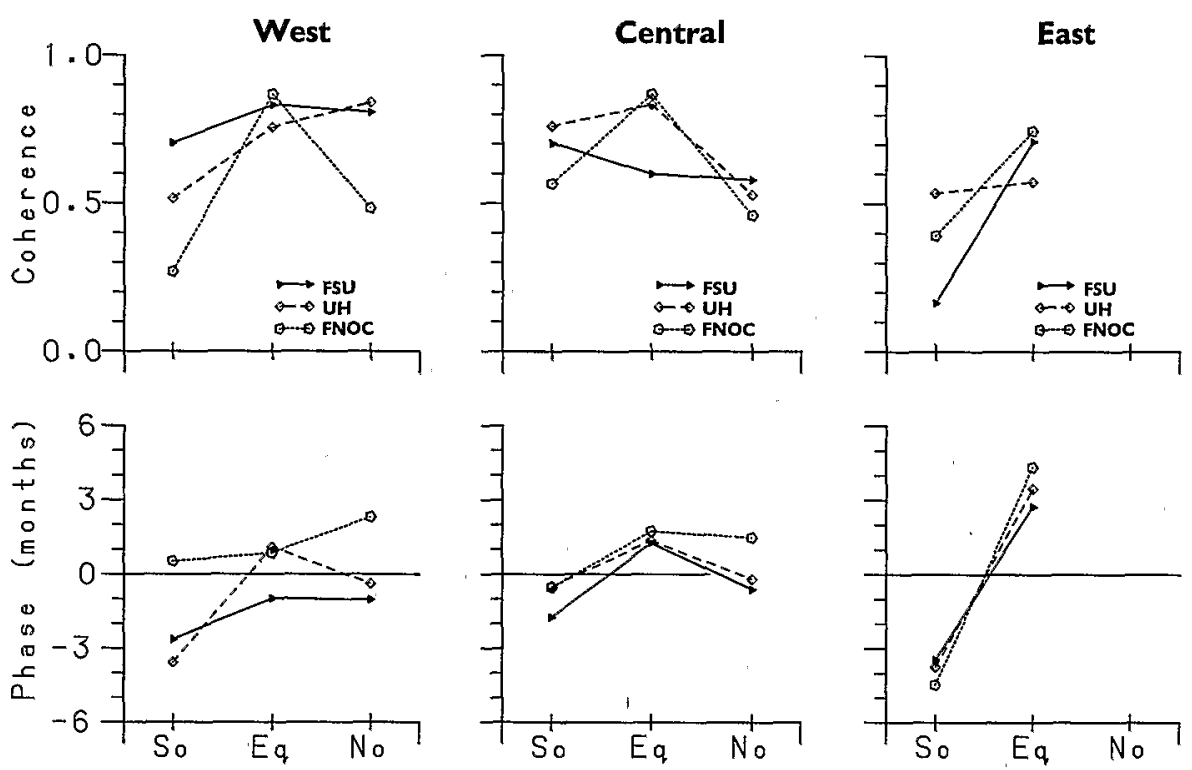

Fig. 15. Coherence and phase at 1 cpy between dynamic heights calculated from XBT data and from the model simulations forced with FSU, UH, and FNOC winds in the eastern, central, and western Pacific. "South" (So) is defined as $5^{\circ}-15^{\circ} \mathrm{S}$, "equator" $(\mathrm{Eq})$ is $5^{\circ} \mathrm{S}$ to $5^{\circ} \mathrm{N}$, and north $(\mathrm{No})$ is $5^{\circ}-15^{\circ} \mathrm{N}$. Coherence is significantly nonzero at the $90 \%$ level of confidence if it exceeds 0.76 . Positive (negative) phase means that dynamic heights calculated from XBT data lead (lag) model simulated dynamic heights.

ic height field in which high wave number variability is amplified. This makes transport estimates more susceptible to contamination by small-scale noise so that in general, transport coherences were smaller than for dynamic height.

As a complementary calculation we computed coherence and phase for model simulations with data from the island sea level network in Figure 3. Table 3 summarizes the results at 1 cpy along with ensemble-averaged amplitudes of the annual harmonic for each sea level data set. We find that the annual harmonic amplitude ranges between a low value of $3.7 \mathrm{~cm}$ for FNOC simulation and $5.6 \mathrm{~cm}$ for the UH simulation. The range of percent variance explained by this harmonic is $69 \%$ for the island data and $81 \%$ for the UH simulation. Coherences are about 0.6 with phase differences of less than 1 month. These results are generally consistent with the coherence relationships along the western and central SOP transects, since most of the islands are in the western and central Pacific. However, phase agreement is better between the FSU and UH simulations and sea level, which may be due to better temporal resolution of the sea level data and to the lack of

TABLE 3. Amplitude and-Percent Variance of Monthly Means Represented by the Annual Harmonic Ensemble Averaged Over the 29 Sea Level Stations Shown in Figure 3 for Tide Gauge Measurements and for Model Simulations

\begin{tabular}{lcccc}
\hline & $\begin{array}{c}\text { Amplitude, } \\
\mathrm{cm}\end{array}$ & $\begin{array}{c}\text { Variance, } \\
\%\end{array}$ & Coherence & Phase \\
\hline Islands & 4.8 & 69 & $\ldots$ & $\ldots$ \\
FSU & 4.6 & 74 & 0.64 & 0.0 \\
UH & 5.6 & 81 & 0.57 & 0.0 \\
FNOC & 3.7 & 78 & 0.62 & 0.9 \\
\hline
\end{tabular}

Also shown are the coherence and phase (in months) between observed sea level and model-simulated sea level. All coherences are significantly nonzero at the $90 \%$ level of confidence, which is 0.48 assuming one in three sea level stations is independent. Positive (negative) phase means that tide gauge sea level leads (lags) simulated sea level. spatial scatter as occurs in the XBT data. Reduction of temporal and/or spatial aliasing in the sea level data may also explain the higher FNOC-sea level coherence $(0.62)$ relative to the FNOC-XBT coherences $(0.30$ in the west and 0.47 in the central Pacific).

\section{Discussion and Conclusions}

In the foregoing sections we have examined simulations of the mean seasonal cycle in the tropical Pacific using a multiple vertical mode version of the Busalacchi and O'Brien [1980] linear model. The model was forced with FSU, UH, and FNOC surface wind stress analyses for the period 1979-1981 and was run to equilibrium for each of four vertical modes. The mean seasonal cycle of dynamic height realtive to 400 dbar was computed and compared with identical calculations based on XBT data for the 1979-1981 period. The XBT data set we used is an augmented version of the ORSTOM-SIO SOP data set in which the number of data was more than quadrupled. We also computed model sea level and compared it with tide gauge data from 29 island stations for 1979-1981.

The wind data sets were compared noting features in the mean and seasonal standard deviations that had an impact on the model results. All wind fields showed the basic large-scale features of the Pacific trade wind system, though the UH winds were the smoothest and the strongest and the FNOC winds were generally the weakest and exhibited the most small-scale structure. FSU winds were intermediate between these two in both smoothness and amplitude. The ITCZ was several degrees closer to the equator in the eastern Pacific in the FNOC product as compared with the UH and FSU products.

Model simulated mean dynamic topographies showed some features in common with the observed topography, for example, the position of the NECC trough and NEC ridge. However, there were a number of discrepancies in the mean between the observations and simulations due to limitations in model physics and in wind forcing functions. North and south 
equatorial ridges were much higher than those observed, North Equatorial Countercurrent troughs were too deep, equatorial ridges near $4^{\circ} \mathrm{N}$ were too weak, and significant equatorial troughs were not generated. One of the most notable distinctions between simulations was the presence of a pronounced mean South Equatorial Countercurrent ridgetrough structure in the FNOC simulation due to a relatively unbroken zonal band of negative curl in the southern hemisphere in the FNOC product.

Observed and simulated mean seasonal height variations were of the order of a few centimeters, and patterns of variability (for example, near the equator and in the vicinity of the NECC trough) were often similar. The seasonal cycle was dominated by the annual harmonic, which accounted for typically $75-90 \%$ of the total variance. Significant coherence levels of $0.5-0.7$, were found at 1 cpy between the observations and simulations. This suggests that about $25-50 \%$ of the observed mean annual variance in dynamic height can be accounted for by the linear model driven by currently available estimates of the surface wind stress. Harmonics higher than the annual were less well modeled because of their weaker signal level.

We found significant regional variations in the coherence and phase calculations for dynamic height at $1 \mathrm{cpy}$. Latitudinally, equatorial (i:e., $5^{\circ} \mathrm{N}$ to $5^{\circ} \mathrm{S}$ ) coherence levels were usually higher than those either to the north or to the south because the ocean responds to the zonal integral of wind stress along the 'equator vis-à-vis spatial gradient of the wind stress' at higher latitudes. Longitudinally, the eastern Pacific was the most poorly modeled region, most likely owing to weak local wind stress forcing and resultant weak oceanic signals.

Confidence limits on our coherence calculations are wide, so it is not possible to determine unambiguously that one wind stress product is superior to the others for simulating the mean seasonal cycle. This is because as was noted in section 3; the large-scale structures in all three products are similar, even though the small-scale structures are quite different. Coherence levels between simulations at $1 \mathrm{cpy}$ were found to be 0.6-0.8, which though slightly higher than coherences with the XBT and the sea level data, are significantly less than unity. This implies that approximately $\frac{1}{3}$ to $\frac{2}{3}$ of the annual variance is incoherent among simulations using the different wind stress products. Given the sensitivity of the model results to the choice of wind forcing, it may be difficult to discern improvements in simulated variability due to more sophisticated model physics and/or physical parameterizations. Thus uncertainty in the surface stress field remains a fundamental obstacle to more accurate modeling of the tropical Pacific sea surface topography on seasonal time scales.

In closing, we note that model sea level signals in all three simulations are largest in the northeastern tropical Pacific (Figures $7 b, 8 b$, and $9 b$ ) and are associated with seasonal movements of the ITCZ (Figures $6 b, 6 d$, and $6 f$ ). However, neither the SOP XBT program nor the sea level network provide data from this region. Given the large amplitude of the wind forcing and of the ocean's dynamical response, a high priority should be given to monitoring this region of the tropics during the TOGA decade. Strong seasonal variations in sea level imply large changes in the meridional redistribution of heat and in the zonal transports of the NECC and NEC. Perturbation of this large seasonal cycle may be important in the evolution of El Niño-Southern Oscillation events by affecting air-sea interaction in the climatically sensitive region of the ITCZ.
Acknowledgments. The authors would like to thank J. J. O'Brien of Florida State University (FSU) for providing the FSU.wind analysis, J. Sadler of the University of Hawaii (UH) for providing the UH wind analysis, and $\mathrm{J}$. Kindle of Naval Oceanographic Research and Development Activity for the FNOC wind analysis. We would like to thank K. Wyrtki of the University of Hawaii for making data from the Pacific island sea level network available to us, and $R$. Tournier of ORSTOM, Nouméa, for help in the dynamic height calculations. D. Moore provided partial support for the authors to visit the Joint Institute for Marine and Atmospheric Research of the University of Hawaii, where several of the ideas in this manuscript were developed. Also, ORSTOM provided travel support for M.J.M. and A.J.B. to work in Nouméa. G. Raymond, D. Allison, V. Fabre, and M. J. Langlade provided programming and technical assistance. Financial support was made available by NOAA's U.S. TOGA Project Office and Equatórial Pacific Ocean Climate Studies (EPOCS) program (M.J.M.), by NASA research task operating plan 161-20-31 and Jet Propulsion Laboratory contract 957647 (A.J.B.) and by ORSTOM and Programme National de la Dynamique du Climat (J.P.). NOAA Pacific Marine Environmental Laboratory contribution 971.

\section{REFERENCES}

Busalacchi, A. J., and M. A. Cane, Hindcasts of sea level variations during the 1982-83 El Niño, J. Phys. Océanogr., 15, 213-221, 1985.

Busalacchi, A. J., and J. J. O'Brien, The seasonal variability in a model of the tropical Pacific, J. Phys. Oceanogr., 10, 1929-1951, 1980.

Busalacchi, A. J., and J. J. O'Brien, Interannual variability of the equatorial Pacific in the 1960s, J. Geophys. Res., 86, 10,901-10,907, 1981.

Busalacchi, A. J., K. Takeuchi, and J. J. O'Brien, Interannual variability in the equatorial Pacific-revisited, J. Geophys. Res., 88, $7551-7562,1983$

Cane, M. A., Modeling sea level during El Niño, J. Phys. Oceanogr., 14, 1864-1874, 1984

Cressman, G. P., An operational objective analysis system, Mon. Weather Rev., 87, 367-374, 1959.

Delcroix, T., G. Eldin, and C. Henin, Upper ocean water masses and transports in the western tropical Pacific $\left(165^{\circ} \mathrm{E}\right), J$. Phys. Oceanogr., 17, 2248-2262, 1987

Donguy, J. R., and G. Meyers, Observed and modeled topography of the $20^{\circ}$ isotherm in the tropical Pacific, Oceanol. Acta, 10, 41-48, 1987.

Eriksen, C. C., M. B. Blumenthal, S. P. Hayes, and P. Ripa, Windgenerated equatorial Kelvin waves observed across the Pacific Ocean, J. Phys. Oceanogr., 13, 1622-1640, 1983.

Gent, P. R., On the annual cycle in the central equatorial Pacific Ocean, J. Mar. Res., 43, 743-745, 1985.

Goldenberg, S. B., and J. J. O'Brien, Time and space variability of tropical Pacific wind stress, Mon. Weather Rev., 109, 1190-1207, 1981

Halpern, D., and D. E. Harrison, Intercomparison of tropical Pacific mean November 1979 surface wind fields, Tech. Rep. $82-1,40 \mathrm{pp}$. Dep. of Meteorol. and Phys. Oceanogr., Mass. Inst. of Technol., Cambridge, 1982.

Harrison, D. E. (Ed.), Report of the ad-hoc committee on surface wind and wind stress fields, Tech. Rep. USTOGA2, Univ. Corp. for Atmos. Res., Boulder, Colo., 1984.

Hayes, S. P., A comparison of geostrophic and measured velocities in the Equatorial Undercurrent, J. Mar Res., 40, suppl., 219-229, 1982

Kessler, W. S., and B. A. Taft, Dynamic heights and zonal geostrophic transports in the centrall tropical Pacific during 1979-1984, J. Phys. Oceanogr., 17, 97-122, 1987.

Large, W. G., and S. Pond, Open ocean momentum flux measurements in moderate to strong winds, $J$. Phys. Oceanogr., 11, 324-336 1981.

Levitus, S., Climatological atlas of the world ocean, NOAA Prof. Pap. 13,173 pp., U. S. Government Printing Office, Washington, D. C., 1982.

McPhaden, M. J., A. J. Busalacchi, J. Picaut, and G. Raymond, A model study of potential sampling errors due to data scatter around expendable bathythermograph transects in the tropical $\mathrm{Pa}$ cific, J. Geophys. Res., this issue.

Meyers, G., The annual Rossby wave in the tropical North Pacific, $J$. Phys. Oceanogr., 9, 663-674, 1979. 
Philander, S. G. H., and R. C. Pacanowski, Nonlinear effects in the seasonal cycle of the tropical Atlantic Ocean, Deep Sea Res., 34, 123-137, 1987.

Philander, S. G. H., and A. D. Seigel, Simulation of El Niño of 1982 83, in Coupled Ocean-Atmosphere Models, Elsevier Oceanogr. Ser., vol. 40, edited by J. C. J. Nihoul, pp. 517-540, Elsevier, Amsterdam, 1985.

Philander, S. G. H., W. J. Hurlin, and A. D. Seigel, Simulation of the seasonal cycle of the tropical Pacific Ocean, J. Phys. Oceanogr., 17, 1986-2002, 1987.

Rasmussen, E. M., and T. H. Carpenter, Variations in tropical sea surface temperature and surface wind fields associated with the Southern Oscillation/El Nịno, Mon. Weather Rev., 111, 353-384, 1982.

Rebert, J. P., J. R. Donguy, G. Eldin, and K. Wyrtki, Relations between sea level, thermocline depth, heat content, and dynamic height in the tropical Pacific Ocean, J. Geophys. Res., 90, 11,719$11,725,1985$.

Roed, L. P., and O. M. Smedstad, Open boundary conditions for forced waves in a rotating fluid, SIAM J. Sci. Stat. Comput., 5, 414-426, 1984.

Sadler, J. C., and B. J. Kilonsky, Deriving surface winds from satellite observations of low-level cloud motions, J. Clim. Appl. Meteorol., 24, 758-769, 1985.

Sadler, J. C., M. A. Lander, A. M. Hori, and L. K. Oda, Tropical marine climatic atlas, II, Pacific Ocean, Tech. Rep. UHMET 87-02, Dep. of Meteorol., Univ. of Hawaii, Honolulu, 1987.
Thompson, K. R., R. F. Marsden, and D. G. Wright, Estimation of low-frequency wind stress fluctuations over the open ocean, $J$. Phys. Oceanogr., 13, 1003-1011, 1983.

Taft, B. A., Geostrophic flow and surface water masses in the central Pacific, in Recent Progress in Equatorial Oceanography, edited by $\mathrm{J}$. P. McCreary, Jr., D. W. Moore, and J. M. Witte, pp. 141-150, editors, Nova University Press, Fort Lauderdale, Fla., 1981.

White, W. B., G. A. Meyers, J. R. Donguy, and S. E. Pazan, Shortterm climatic variability in the thermal structure of the Pacific Ocean during 1979-1983, J. Phys. Oceanogr., 15, 917-935, 1985.

Wyrtki, K., Fluctuations of the dynamic topography in the Pacific Ocean, J. Phys. Oceanogr., 5, 450-459, 1975.

Wyrtki, K., Water displacements in the Pacific and the genesis of El Niño, J. Geophys. Res., 90, 7129-7132, 1985.

Wyrtki, K., and W. Leslie, The mean annual variation of sea level in the Pacific Ocean, Rep. HIG-80-5, 159 pp., Univ. of Hawaii, Honolulu, 1980.

A. I. Busalacchi, Laboratory for Oceans, NASA Goddard Space Flight Center, Greenbelt, MD 20771.

M. J McPhaden, NOAA Pacific Marine Environmental Laboratory, 7600 Sand Point Way N.E., Seattle, WA 98115.

J. Picaut, Groupe SURTROPAC, Office de la Recherche Scientifique et Technique Outre-Mer, Nouméa, New Caledonia.

(Rećeived August 7, 1987;

accepted January 25, 1988.) 